\title{
Gender differences in information and communication technology use \& skills: a systematic review and meta-analysis
}

\author{
Atika Qazi ${ }^{1}$ (D) - Najmul Hasan ${ }^{2}$. Olusola Abayomi-Alli ${ }^{3}$. Glenn Hardaker ${ }^{1}$. \\ Ronny Scherer ${ }^{4}$ - Yeahia Sarker ${ }^{5}$. Sanjoy Kumar Paul ${ }^{6}$. Jaafar Zubairu Maitama ${ }^{7}$
}

Received: 16 August 2021 / Accepted: 30 September 2021 / Published online: 21 October 2021

(c) The Author(s), under exclusive licence to Springer Science+Business Media, LLC, part of Springer Nature 2021

\begin{abstract}
Even though information and communication technology (ICT) is essential for everyday life and has gained considerable attention in education and other sectors, it also carries individual differences in its use and relevant skills. This systematic review aims to examine the gender differences in ICT use and skills for learning through technology. A comprehensive search of eight journal databases and a specific selection criterion was carried out to exclude articles that match our stated exclusion criteria. We included 42 peer-reviewed empirical publications and conference proceedings published between 2006 and 2020. For a subsample of studies, we performed a small-scale meta-analysis to quantify possible gender differences in ICT use and skills. A random-effects model uncovered a small and positive, yet not significant, effect size in favor of boys $(g=0.17,95 \%$ CI $[-0.01,0.36])$. However, this finding needs to be further backed by large-scale meta-analyses, including more study samples and a broader set of ICT use and skills measures. We highlight several concerns that should be addressed and more thoroughly in collaboration with one another to better IT skills and inspire new policies to increase the quality of ICT use. The findings from this review further suggest implications and present existing research challenges and point to future research directions.
\end{abstract}

Keywords Gender differences · Information and communication technology $\cdot$ ICT use and skills · meta-analysis · A systematic review

Atika Qazi

atikaqazium@gmail.com

Extended author information available on the last page of the article 


\section{Introduction}

The term Information and Communication Technology (ICT) refers to all likely techniques that are being used for processing and communicating information such as computer technology, smartphones, multimedia, network hardware, software (Anderson, 2008), the Internet, the online reviews (Qazi, Raj, Tahir, Cambria, \& Syed, 2014b; Qazi, Raj, Tahir, Waheed, et al., 2014c). Online reviews are rapidly growing via the Internet and are helpful (Qazi et al., 2013; Qazi et al., 2016; Qazi, Fayaz, \& Raj, 2014a) for readers to take important decisions in diverse fields of interest. The importance of ICT has played a major key role in developing research endeavors. The ICT applications are almost everywhere, such as education, health, banking, business, and political sectors, and these applications have their style of usage that varies across countries and regions. For example, the use of ICT for education provides enabling tools for the learning environment. Teachers and students can teach and learn in a practical, active, and self-directed style (Qazi, Hardaker, et al., 2021a). The research into the Internet and computer access, use, and skills remain predominantly focused on the most commonly used ICT-oriented devices in educational institutes (Losh \& Society, 2003). Therefore, the research work included in this review is related to use, and skills differences are covered from the educational domain.

The constantly changing learning environment has increased emphasis on ICTs to acquire and enhance learning abilities and thrive in today's fast-moving world. The use of ICTs is becoming one of the most fundamental building blocks of contemporary civilization in a relatively short period. Similarly, ICT adoption as a foundational academic standard is one of the most significant transformation processes over the decade (Nketiah-Amponsah et al., 2017). Several studies have examined the use of ICT by students and the connection between ICT usage and academic achievement. The effect of ICT on education is directly associated with students' access to and usage of digital devices. Studies showed that females have limited access to ICT than their male counterparts (Mumporeze \& Prieler, 2017). Despite the widespread use of ICT by educational institutions, many studies have shown a gender imbalance in ICT usage and skill development. A significant number of students (particularly boys) have a more positive view of ICT and utilize it to improve their learning (Lee et al., 2019; Tam et al., 2020). While significant progress has been made in ICTs, there remains a severe territorial and gender technological inequality. Many studies exist that contradict each other on the matter of gender differences in ICT use, while some studies have shown differing results in that some claim benefits for females. In contrast, others offer benefits for boys (Siddiq \& Scherer, 2019a, 2019b). Because of the disparities in access to and use of ICTs between men and women, more study is required to understand the implications strategies of ICT usage and skill development. The conflicting results need a closer look at the relationship between ICT use, skill development, and gender. To make a significant contribution to addressing the gap and moving forward existing knowledge, this systematic review and metaanalysis may assist policymakers by offering existing insight into ICT use and skills, which can be used to further the implication of ICTs in their work and policies. 
The education system continues to become more ICT-oriented due to its growing capabilities in learning and training. Since the development of the core ICT tools such as computers and the Internet, we began to see significant changes to conventional instruction methods. ICTs are critical in the current times, and notably during the global crisis of the COVID-19 pandemic, to continue education (Qazi et al., 2020). Consequently, ICT literacy has become crucial in helping people with essential competencies and success skills in educational institutes (König et al., 2020; Qazi, Qazi, et al., 2021b). It seems to reflect the emphasis on ICT and education due to their instrumental role in shaping our lives. Despite the rapid progress of ICT, there is variable acceptance and usage of ICT applications among students and teachers. Moreover, this difference of attitude is determined by many factors such as demographics (age, gender, education) (Anandhita \& Ariansyah, 2018), ethnicity, religion, social, and economics (Oldeweme et al., 2021; Rahiem, 2020; Wilhelm \& Society, 2018. All this difference affects the pupils' learning outcomes and attitudes towards access and use of ICT. However, gender differences are crucial and need to be explored in terms of a systematic review (Basavaraja et al., 2017; Gnambs, 2021) Therefore, this study focuses on understanding how ICT uses and related skills influence students and teachers.

In addition, some previous meta-analyses and reviews have reported findings from ICT literacy, knowledge, skills and satisfaction, self-efficacy factors; and socioeconomic status; (Lahti et al., 2014; Lei et al., 2021; Siddiq \& Scherer, 2019a); despite research showing a lack of association between gender differences and skills and use of ICT for educational context (Lahti et al., 2014). Consequently, there is a lack of systematic reviews and meta-analyses providing an overall view of ICT use and skills differences, which is important to investigate as statistical significance strengthens the validity of any differences. The purpose of this study is to conduct a systematic literature review and synthesize the findings to examine the extent of difference between girls and boys in terms of ICT usage and skills. Therefore, we have proposed two research questions (RQ1 and RQ2) in this systematic review, and we have responded to both questions on the published evidence-based research.

The major contributions of this study are as follows.

- Investigated the gender differences concerning use \& skills in adopting ICT practices in the last decade.

- Meta-analysis is performed to quantify gender differences in ICT use and skills and their variation between studies.

- This SLR provides the opportunity to combine current material, provide robust explanations, and draw the groundwork for future research into gender differences in ICT usage and skill development.

\section{Related works}

The systematic literature review (SLR) uses systematic and explicit methods to identify and formulate questions transparently and select relevant research, appraise critically, and analyze data from the studies included in the review (Moher et al., 2009). Most of the previous literature reviews research on gender variations in the 
ICT context has taken a cross-sectional approach, and little is known about the access and use skills disparities during a person's life (Gnambs, 2021). As a result, the current research investigates ICT skills and use differences for a total of 42 relevant articles. The studies related to ICT are mostly associated with learning and education and standalone information systems such as the utility and impact of ICT (Webb et al., 2017), improving the performance of the student and the learning environment (Asad et al., 2020); the students' interest for using ICTs and e-learning into science and social science courses and assist teachers in teaching process in higher education; mobile and ubiquitous learning in higher education settings (Pimmer et al., 2016); to encourage self-directed learning in science classes (Stevenson et al., 2017); to look into the students' perceptions of religious instruction (Karakostantaki et al., 2021); find out how e-learning affects nursing education (Voutilainen et al., 2017); ICT and e-learning in nursing education (Button et al., 2014); examining the effectiveness of blended-team based learning (TBL) in higher education (River et al., 2016); blended learning and analysis of factors affecting the use of ICT in education (Deshpande \& Shesh, 2021); challenges in online component of blended learning (Rasheed et al., 2020); Scaffolding students peer-learning self-regulation strategy in the online component of blended learning (Rasheed et al., 2021); Massive open online courses (MOOCs) for today's education by offering a global accessible form of online learning (Rasheed et al., 2019); identifying emerging trends of learning technologies for special education (Liu et al., 2013); internet-based learning for clinician behaviour and patient outcomes (Sinclair et al., 2016); technologyimproved, self-regulated learning tools in the school of healthcare (Petty, 2013); in nursing education, the use of videos is practised to support learning and teaching clinical skills (Forbes et al., 2016); and the use of e-Learning in radiology teaching at the undergraduate level (Zafar et al., 2014). Despite the recognized advantages of e-learning, research has also shown that it has a detrimental effect on student s' psychological distress due to e-learning systems crack-up during COVID-19 (Hasan \& Bao, 2020). Nevertheless, in recent years, there are no specific systematic review studies related to ICT differences in terms of ICT use and skills for the education domain. This paper attempts to cover the research gap by providing a rapid systematic review of ICT gender differences with a focus on use and skills for the education domain. There is a focus on the education sector due to the research to date that has been conducted. This review paper followed the broadly adopted guidelines by (Ashraf et al., 2017; Keele, 2007; Seuring \& Müller, 2008; White \& Schmidt, 2005) as explained below in detail.

\section{Research method}

This review paper presented a rapid systematic review and followed the broadly adopted guidelines by (Ashraf et al., 2017; Keele, 2007; Martin et al., 2020; Seuring \& Müller, 2008; White \& Schmidt, 2005; Xia et al., 2018) as explained below in detail in objectives and research questions of the review. The review procedure followed the guidelines and consisted of three steps: (a) searching the research, (b) evaluating relevancy, and (c) data extraction. The major findings and 
contributions of the papers were then explored by conducting a thematic analysis. The main objective of conducting this systematic literature review is to understand the gender differences in usage and skills of ICT for the education domain and the extent to which gender differences vary between studies. In light of these objectives, the following research question (s) (RQ) are proposed.

RQ 1: To what extent do gender differences exist in the use and skills of ICT applications?

RQ 2: How much do gender differences differ between studies? (Overall effect size and variation between studies)?

\subsection{Formal strategy}

A standard Boolean search string is established when the study goals and questions have been defined (Ashraf et al., 2017; Keele, 2007; Seuring \& Müller, 2008; White \& Schmidt, 2005). Formulating a standard Boolean search string (Dieste et al., 2009) will analyze available research material related to research goals. For this, the search space is explained by famous electronic sources or repositories and databases to gather the relevant articles as listed in Table 1.

\subsection{Search string}

According to the proposed research questions, the following keywords for search string are selected in a combination of both keywords with full "Information and communication technology "and "Information technology" and with abbreviation's "ICT" and "IT," i.e.: ("Information technology" OR "Information and communication technology" OR “IT" OR "ICT”) AND ("gender" OR "learning” OR "use and skills", "OR" "Gender differences" OR "use and access" OR "differences", OR "technology-based learning" OR "gender digital divide" OR" digital inequality.”.

Table 1 Search Sources and relevance appraisal

\begin{tabular}{ll}
\hline Electronic sources & $\begin{array}{l}\text { ACM Digital Library, IEEE } \\
\text { Xplore, Springer, Google Scholar, } \\
\text { ScienceDirect, Wiley, Emerald, } \\
\text { Web of Science Springer, Google } \\
\text { Scholar, ScienceDirect, }\end{array}$ \\
\hline Selected items & $\begin{array}{l}\text { Journal and conference papers } \\
\text { Tearch applied on }\end{array}$ \\
& $\begin{array}{l}\text { To identify publications that are } \\
\text { and are defined by our search } \\
\text { keywords in the title or abstract, } \\
\text { we use the full-text option }\end{array}$ \\
Language & English \\
\hline
\end{tabular}




\subsection{Inclusion \& exclusion criteria}

There were many irrelevant articles produced as a consequence of the results of the preceding stages. Thus, we created a set of inclusion and exclusion criteria to better identify irrelevant articles. This study presented and categorized different criteria phases for the overall selection. The inclusion and exclusion criteria used in this study were classified as depicted in Table 2. Finally, the results of a preliminary study are considered, and 42 relevant research are examined.

\subsection{Meta-analysis of the gender differences in ICT use \& skills}

The studies with complete information required for effect size calculations were shortlisted from RQ1a against RQ1b. After the screening for eligibility, $k=15$ studies were further evaluated for effect sizes calculation and presented in subsections 5.5 and 5.6. ICT skills allow one to use digitally available information and/ or digital device to understand any topic of interest. Gender differences in ICT use and skills were reported in the primary studies in various methods, including mean scores and standard deviations or derived statistics such as Cohen's $d$ as an effect size, $t$-values, and $F$-values (Cohen, 1992). We converted effect sizes into Hedges' $g$ (Lipsey \& Wilson, 2001). The effect size and the respective sampling variance was computed as follows:

$$
E S=\frac{\bar{X}_{B}-\bar{X}_{G}}{S D_{\text {Pooled }}}
$$

$\bar{X}_{B}$ and $\bar{X}_{G}$ represent the mean scores of boys and girls; $S D_{\text {Pooled }}$ represents the pooled standard deviation, which is calculated as follows:

Table 2 Summary of Sub-Categories of Inclusion and Exclusion Criteria

\begin{tabular}{lll}
\hline Criteria & Sub-Categories & Descriptions \\
\hline Inclusion & I1 & Peer-reviewed publications are studied. \\
& I2 & Publications must have been published in English. \\
& I3 & Papers should present an empirical study of ICT use and/or skills. \\
& I4 & Studies published between 2006 and 2020 \\
Exclusion & E1 & Studies in which ICT differences are not explicitly focused but \\
& E2 & only refer to ICT applications \\
& E3 & Studies in which ICT access and use is not discussed \\
& E4 & Studies in which inclusion criteria are not met \\
& Removal of viewpoint, keynote, comments, tutorials, editori- \\
& & als, prefaces, and discussions, irrelevant presentations in slide \\
& formats
\end{tabular}




$$
S D_{\text {Pooled }}=\sqrt{\frac{\left(N_{G}-1\right) S D_{G}^{2}+\left(N_{B}-1\right) S D_{B}^{2}}{N_{G}+N_{B}-2}}
$$

$N_{G}$ and $N_{B}$ represent the sample sizes of the subsamples of girls and boys, and $S D_{G}^{2}$ and $S D_{B}^{2}$ their respective variances. We then transformed the effect size ES into Hedges' $g$ (with $d f=N_{G}+N_{B}-2$ ):

$$
g=\left(1-\frac{3}{4 d f-1}\right) \cdot E S
$$

The corresponding sampling variance $v_{g}$ and the standard error $S E_{g}$ were then calculated as follows (Borenstein et al., 2017):

$$
\begin{gathered}
v_{g}=\left(1-\frac{3}{4 d f-1}\right)^{2} \cdot\left(\frac{N_{G}+N_{B}}{N_{G} \cdot N_{B}}+\frac{E S^{2}}{2\left(N_{G}+N_{B}\right)}\right) \\
S E_{g}=\sqrt{v_{g}}
\end{gathered}
$$

To synthesize the resultant effect sizes and quantify between-study variation, we specified univariate random-effects models and compared them to fixed-effects models. We performed all analyses in the R packages metafor (Viechtbauer, 2010), meta (Balduzzi et al., 2019), and dmetar (Guilhamon et al., 2013). Overall, the meta-analysis of the standardized mean differences was aimed at synthesizing the quantitative indicators of gender differences in the sample of selected studies. However, given the limited number of primary studies qualifying for our meta-analysis, the weighted average effect size cannot be generalized across the entire body of research; any inference is drawn on this effect size and its variation is limited to the meta-analytic sample.

\section{Search, screening, and coding of studies}

The search findings and extraction of information from electronic repositories are presented in this section.

\subsection{Study search \& selection}

Followed by the search strategy, the studies were retrieved via the preferred electronic repositories. In the original search, 367 studies were extracted as described in Table 3. Following the application of the inclusion criteria, the titles and abstracts of studies are thoroughly assessed by a dedicated researcher (Round 1). There are 170 studies that remain after this first round is completed. The preselected papers were then assessed in Round 2 to apply the exclusion criteria (E1, E2, E3, and E4), followed by a co-author of the paper and a researcher with experience in the subject. In this assessment, from researchers, there could be agreements and disagreements. 
Table 3 Identified studies during the systematic search

\begin{tabular}{ll}
\hline Electronic sources & Retrieved \\
\hline ACM Digital Library & 10 \\
IEEE Xplore & 15 \\
Springer & 70 \\
Google Scholar & 13 \\
ScienceDirect & 221 \\
Wiley & 12 \\
Emerald & 20 \\
Web of science & 6 \\
\hline
\end{tabular}

Therefore, a face-to-face meeting of consensus was conducted. In case of conflicting consensus on the papers, the two researchers go through the entire article, and by looking into the defined exclusion criteria, the paper is excluded. Lastly, we have obtained 42 studies out of 367 from the different databases (see Table 3 ).

\subsection{Data extraction \& synthesis}

As shown in Fig. 1, a data extraction procedure (Brereton et al., 2007) was used to find important information from the 42 primary papers included in the analysis. The following steps are included for the data extraction process: firstly, a form is prepared to note down ideas, contributions, concepts, and findings of the selected 42 studies. The data extracted from the publication consist of the following: (a) review data, (b) authors; (c) title; (d) database; (e) references; (f) topic relevance, i.e., ICT and computer and Internet and related approaches ( $g$ ) future work; (h) in-depth analysis (i) year of publication. After the completion of extraction, content analysis was used to describe each study's focus (Elo \& Kyngäs, 2008). Various studies have employed content analysis, such as recently used in a systematic review study (Qazi et al., 2017). To evaluate the result of data extraction, the kappa coefficient (Fleiss et al., 2013) is followed by an inter-rater agreement amongst researchers. Kappa is a statistical agreement metric (Fleiss et al., 1981), which shows a good agreement (Landis \& Koch, 1977) equal to 0.5 for this work. Afterward, to ensure quality, quality assessments were performed for selected studies. The SLR study selection procedure is shown in Fig. 1.

\subsection{Methodology quality assessment}

The quality criterion for this systematic review is followed by other studies from diverse knowledge domains (Qazi et al., 2015; Qazi et al., 2019). The criteria shown in Table 4 depicted the quality of studies used throughout this review, respectively. Following the requirements defined as $(\mathrm{C} 1)$, the research aims and objectives were evaluated if they are well defined. For this question, $90 \%$ of the studies answered positively. For the second criterion (C2) research, the context was checked for a proper explanation. For this question, $92 \%$ of the studies 


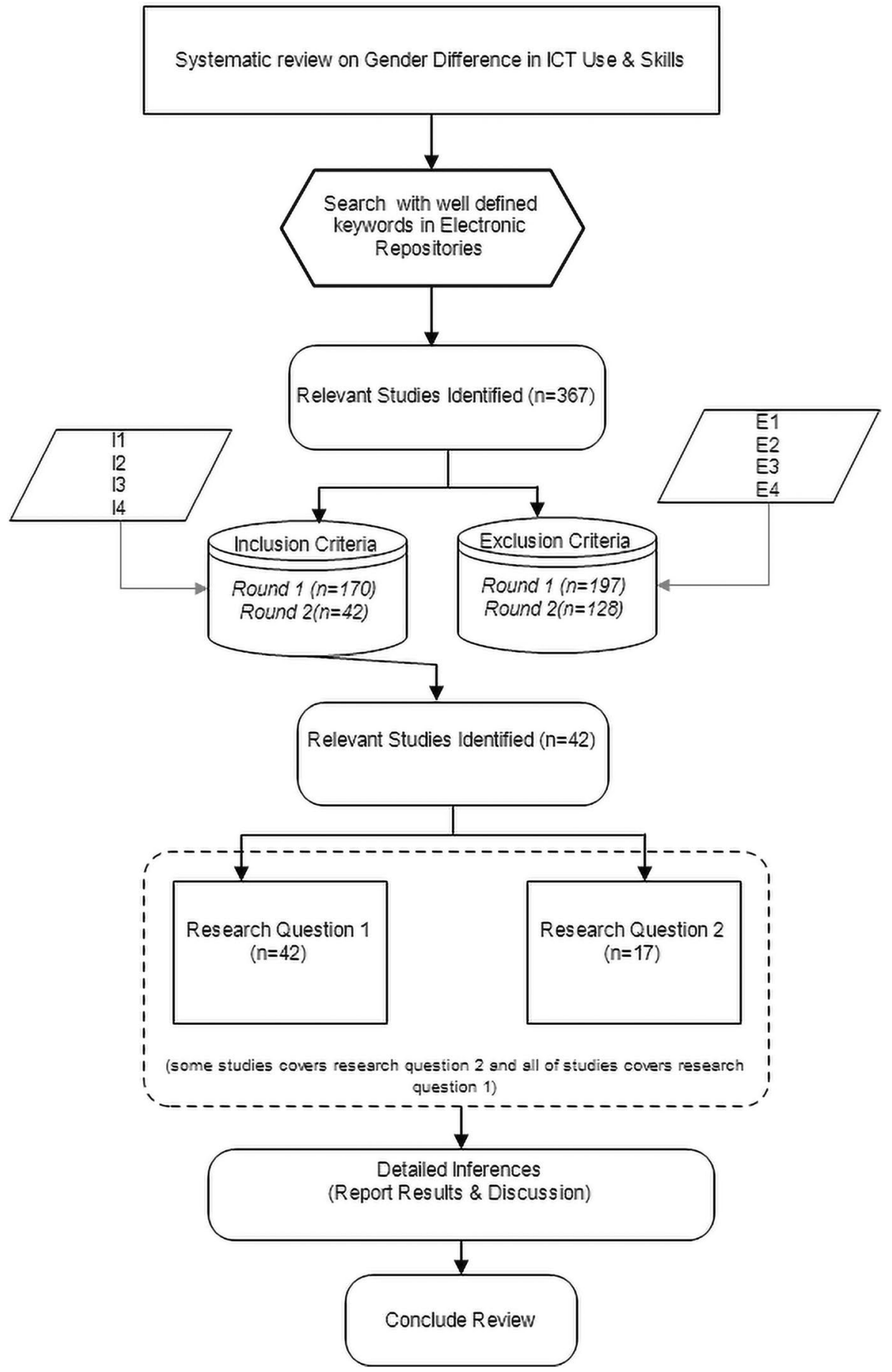

Fig. 1 Flowchart for the study process 
Table 4 Quality assessment criteria of selected studies

\begin{tabular}{|c|c|c|}
\hline Criteria & Response Grading & Grade obtained \\
\hline (C1) Is the research aim clearly described? & (Yes, nominally, No) & $90 \%$ \\
\hline $\begin{array}{l}\text { (C2) Is the research context } \\
\text { properly explained? }\end{array}$ & (Yes, nominally, No) & $92 \%$ \\
\hline $\begin{array}{l}\text { (C3) What is the acceptance quality rate for paper } \\
\text { based on the findings? }\end{array}$ & $\begin{array}{l}>80 \%=1,<20 \%=0, \text { in- } \\
\text { between }=0.5\end{array}$ & $92 \%$ \\
\hline
\end{tabular}

positively answered. The last question was evaluated to see if it was good enough for our research purpose. A group of competent researchers and an independent reviewer then created the heuristic scores for the quality measures (C3). Figure 2 depicts the normalized scores based on the quality scores of the selected studies.

\section{Results}

The result obtained from the meta-analysis conducted from the relevant articles for RQ1 (a) is sectioned and described extensively using the PICO model.

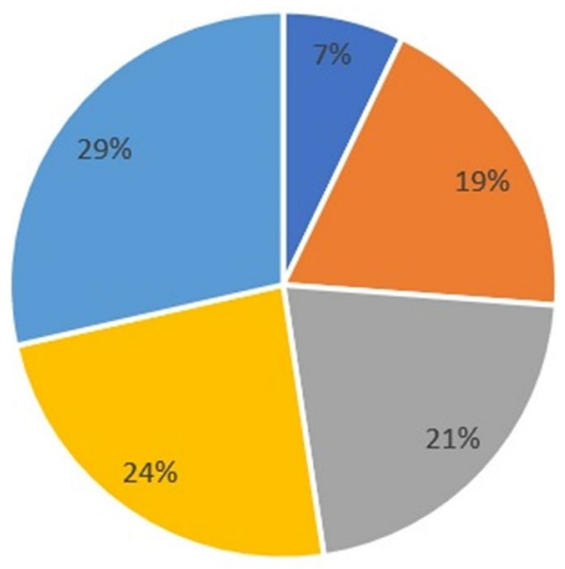

a $<20 \%$ Poor $=20-45 \%$ Fair $=46-65 \%$ Good $=66-85 \%$ Very good $=>85 \%$ Excellent

Fig. 2 The quality percentages of selected studies 


\subsection{Population analysis}

The population analysis in this study is based on quantitative and qualitative measurements based on the percentiles of the chosen samples. The population analysis is sub-grouped into which are:

\subsubsection{Gender differences and participation in studies}

The quantitative analysis of gender participation is measured based on a male to female ratio in contributions from the selected papers. We calculated the percentage of gender differences presented in the studies as depicted in Fig. 3.

\subsubsection{Population impact based on participant}

This study emphasizes the need to evaluate the selected study type of participant their research survey focuses on. The 42 relevant articles' interesting observations show that previous studies have tried to impact all variants of participants ranging from student, teachers, combined, etc., as depicted in Fig. 4.

\subsubsection{Publication year and study distribution in the last decade}

To measure research progress in the domain area of ICT in education, emphasizing bridging gender differences. This study scope is focused on relevant studies in the last decade, as summarized in Fig. 5. The total percentage of countries where the study had been conducted lately is represented in Fig. 6 the countries such as Spain, Belgium. Finland and South Africa have the highest number of study participation.

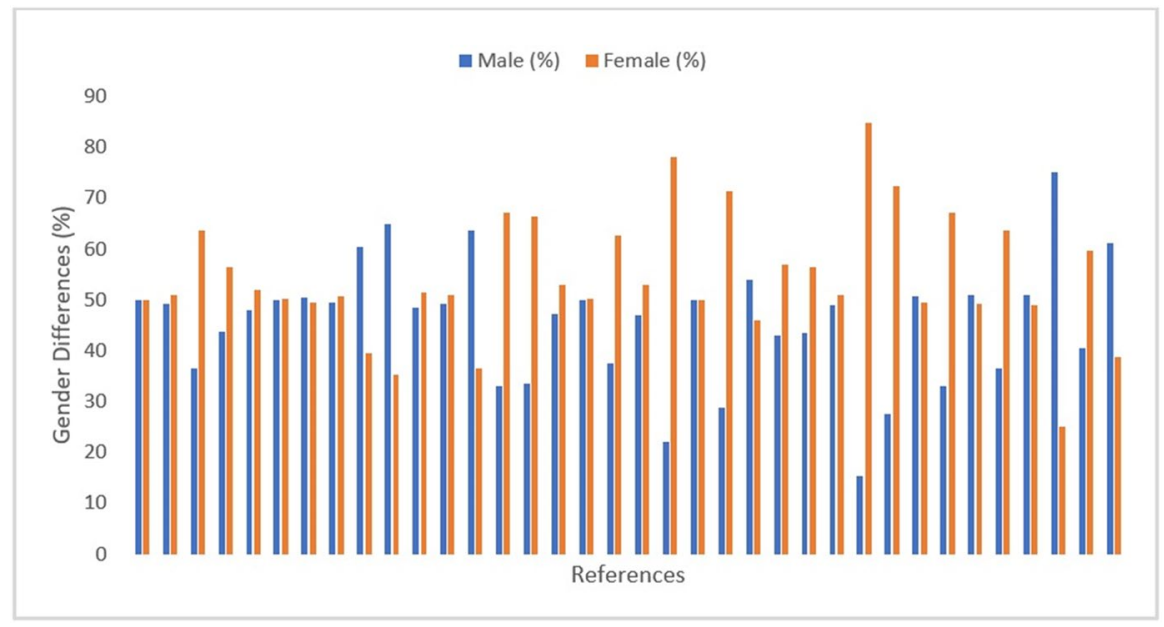

Fig. 3 The population percentages based on gender differences from selected publications 


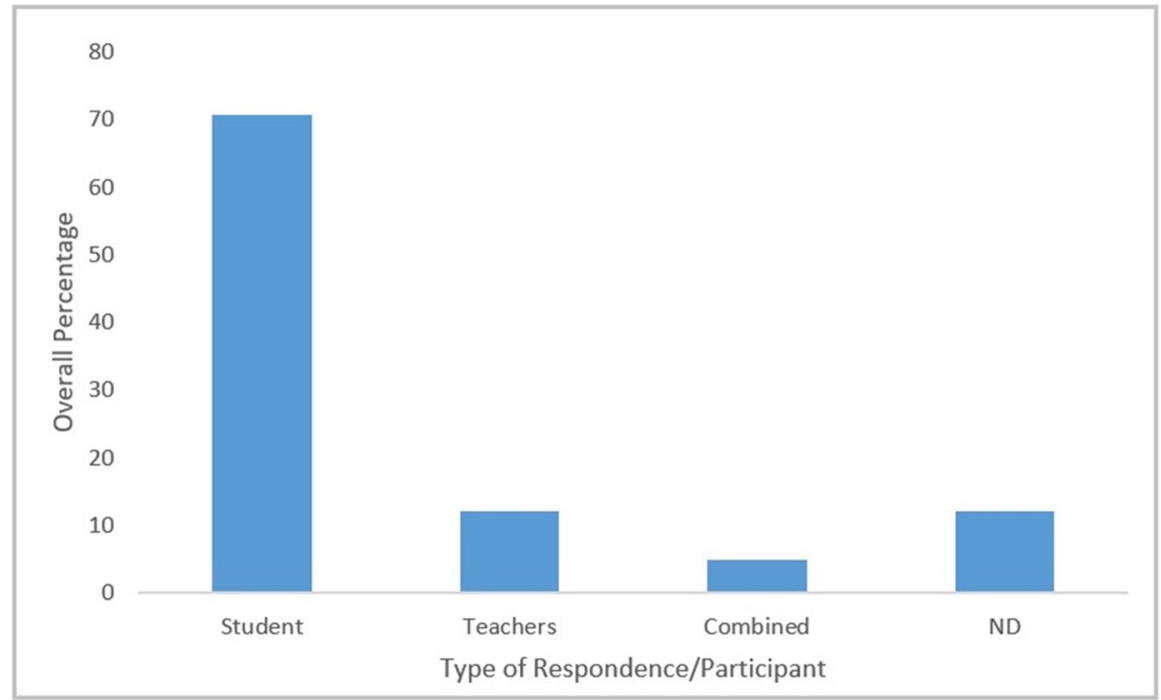

Fig. 4 The population percentages based on the type of participants

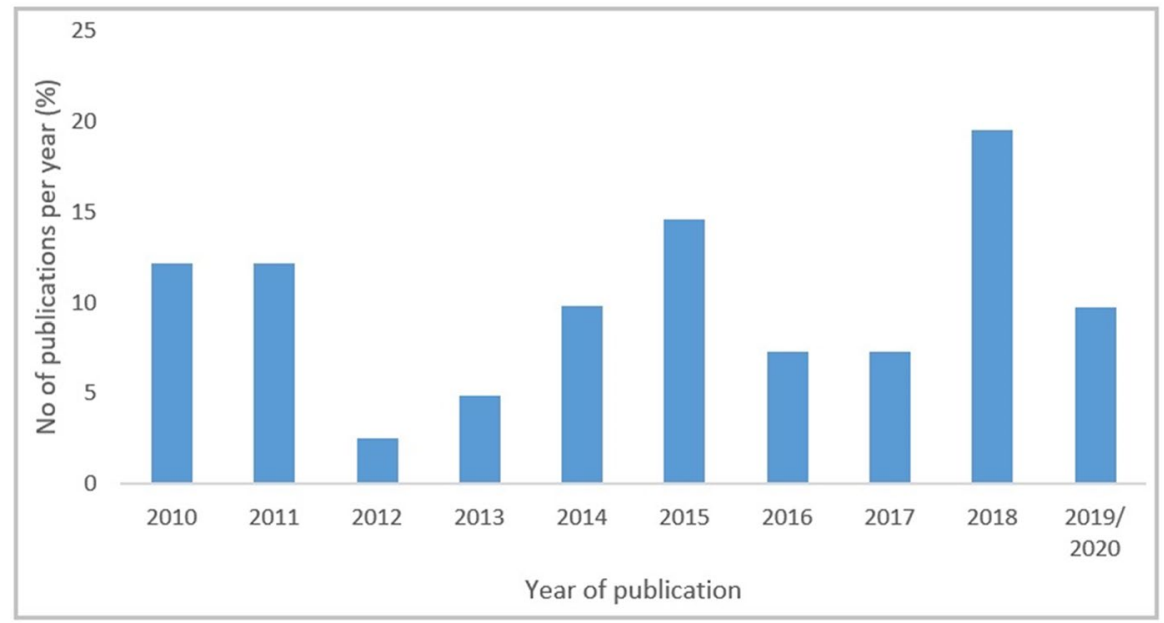

Fig. 5 The percentage of selected publication years in the last decade

\subsubsection{Peer-review sources}

A table of peer source categories and the different sources of articles used in this study are depicted in Table 5 . 


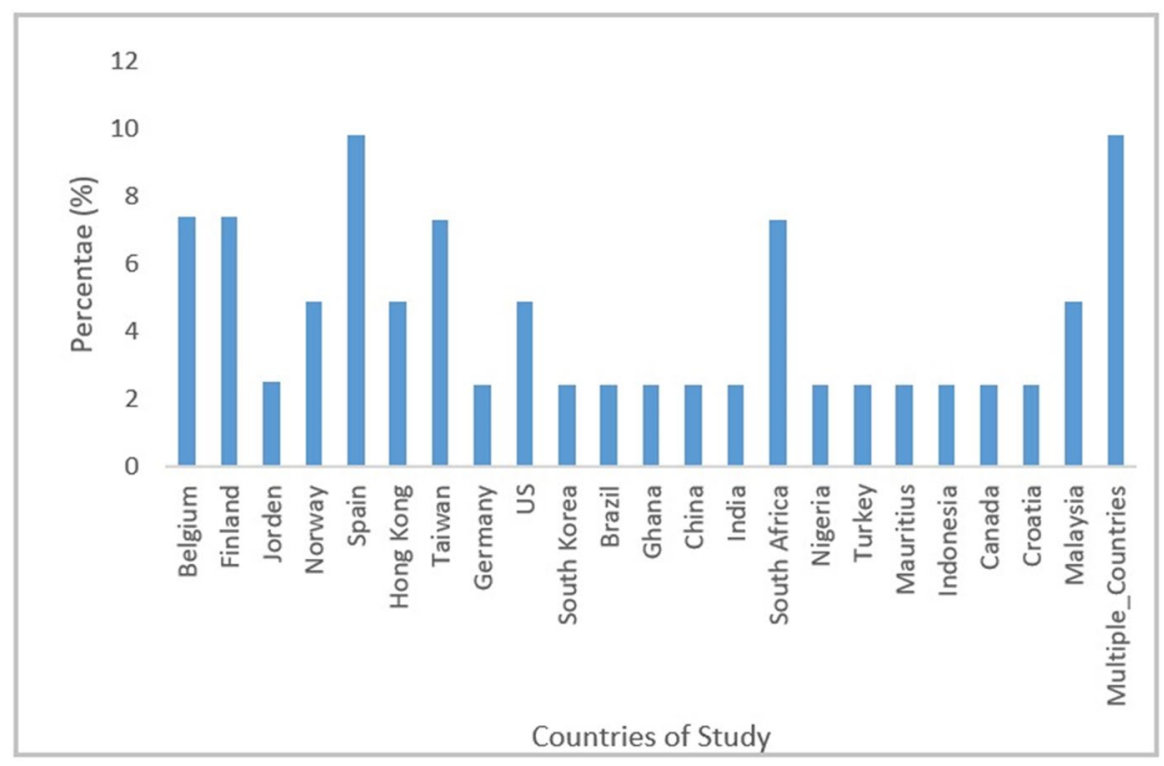

Fig. 6 The percentage of study per country

\subsection{Analysis based on intervention}

The analysis of intervention carried out on the selected articles was evaluated based on the percentage of sampling methods used in Fig. 7. We also evaluated the various sampling method types in the selected articles, as presented in Fig. 8. The studies that have not described sampling methods are represented by ND (not described).

\subsection{Comparative analysis}

This subsection analyzed and compared the different measurements. The reliability measure was evaluated using the number of citations of each model. T-test has the highest citations. This model is one of the most widely used models in the selected articles to measure results' reliability, as shown in Fig. 9. We also evaluated the study performance as either observation, report card, or theoretical performance, as presented in Fig. 10.

\subsection{Outcome analysis}

We analyzed the outcome of the selected publications based on some of the metadata stated in the literature. A qualitative analysis of the different outcome types, such as computer tools, competence, self-efficacy, computer attitude, skills, and 
Table 5 Summary of sources of selected articles

\begin{tabular}{|c|c|}
\hline Category & Sources of selected articles \\
\hline Conferences & $\begin{array}{l}\text { International Journal of Emerging Technologies in Learning (iJET) } \\
\text { International Conference on Advanced Computer Science Applications and Technologies } \\
\text { (ACSAT) } \\
\text { IEEE International Conference on Teaching, Assessment, and Learning for Engineering } \\
\text { (TALE) } \\
\text { 33rd International Conference on Information Technology Interfaces } \\
\text { 47th Hawaii International Conference on System Sciences } \\
\text { 6th International Conference on Electrical Engineering and Informatics (ICEEI) } \\
\text { International Conference on ICT for Rural Development } \\
\text { International Conference on Information Science and Digital Content Technology } \\
\text { European Conference on Information Literacy }\end{array}$ \\
\hline Journal & $\begin{array}{l}\text { Asia-Pacific Education Research } \\
\text { Computers and Education } \\
\text { Computers in Human Behavior } \\
\text { Educational Technology Research and Development } \\
\text { Gender, Technology, and Development } \\
\text { Heliyon } \\
\text { Interactive Technology and Smart Education } \\
\text { International Journal of Africa Nursing Sciences } \\
\text { International Journal of Digital Library Services } \\
\text { International Journal of E-Learning and Educational Technologies in the Digital Media } \\
\text { Journal of Diversity and Gender Studies } \\
\text { Journal of Educational Research } \\
\text { Journal of International Development } \\
\text { Journal of Retailing and Consumer Services } \\
\text { Journal of Vocational Behavior } \\
\text { Learning and Individual Differences } \\
\text { Procedia-Social and Behavioral Sciences } \\
\text { SIGMIS Database: the DATABASE for Advances in Information Systems } \\
\text { Sustainability } \\
\text { The Electronic Library }\end{array}$ \\
\hline
\end{tabular}

internet usage, is presented in Fig. 11 and the number of citations per category of tools for evaluation is given in Fig. 12.

\subsection{Meta-analysis RQ1 (b)}

ICT facilitates access to electronic information, and its tools have always helped extend information and complement traditional learning. Various ICT skills are required to use the ICT tools for both students' and teachers' working in academia. Therefore, this meta-analysis includes studies describing gender differences in the use of ICT and related skills. For primary studies to be included, they had to provide 


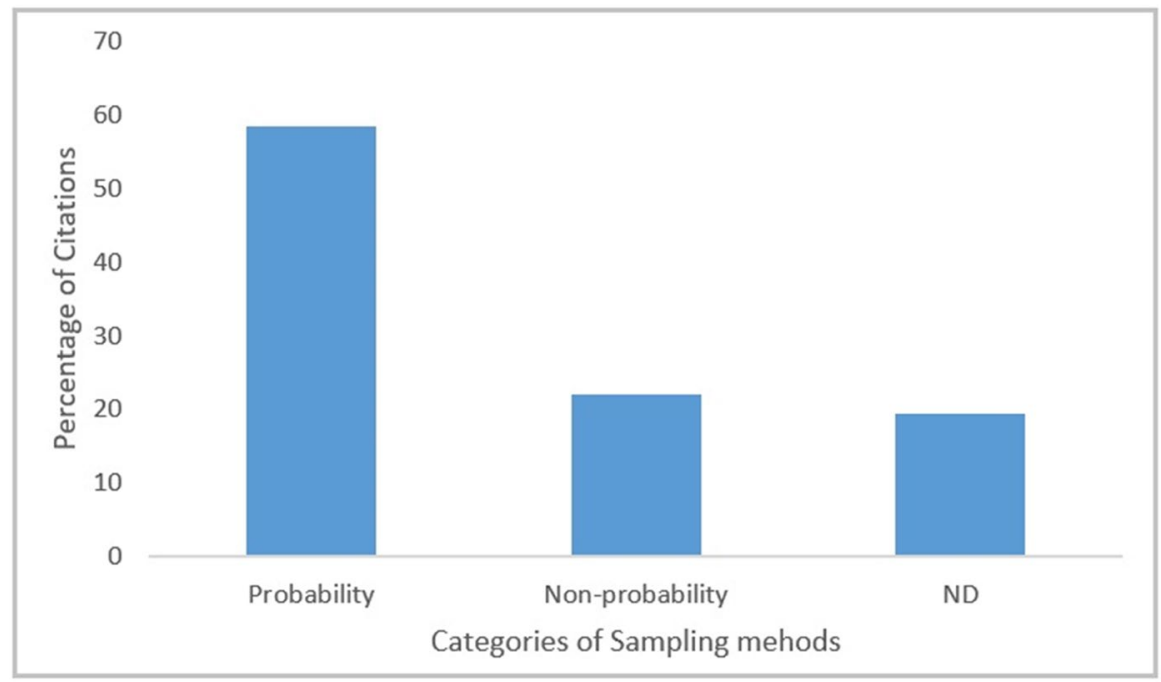

Fig. 7 Percentage of sampling methods used in selected publications

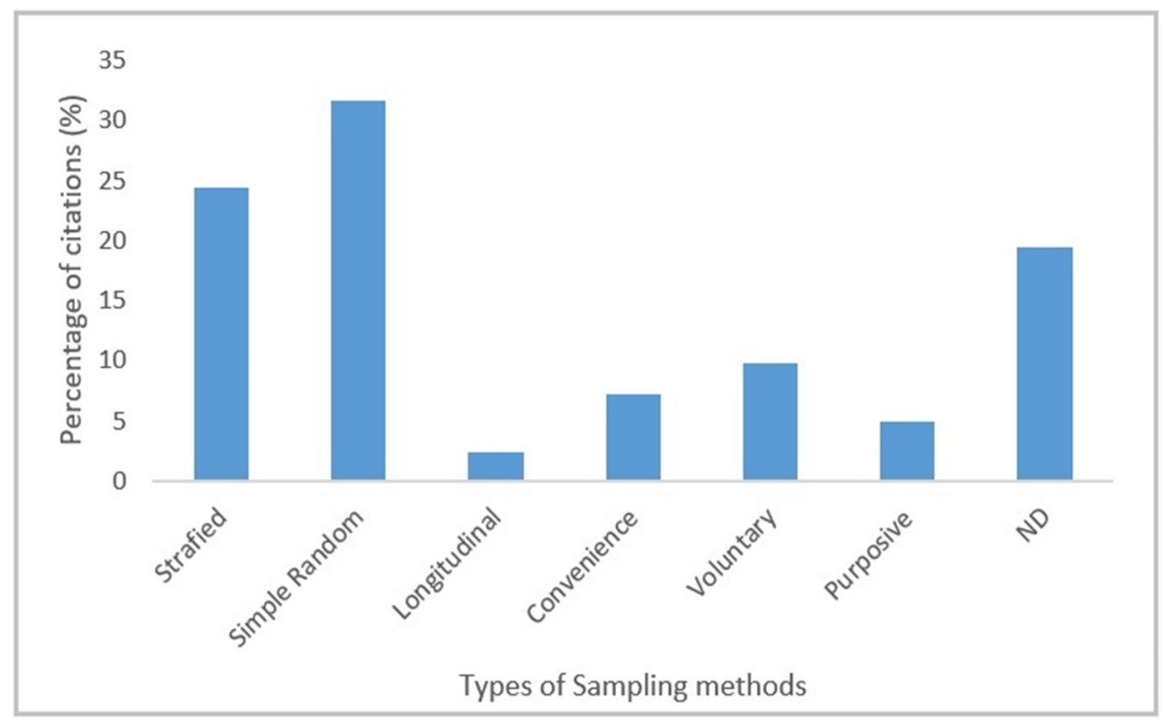

Fig. 8 Percentage of sampling method types used in the selected publication

sufficient information to calculate effect sizes; overall, 15 primary studies could be included from the existing study pool to answer RQ1 (b).

Given the small number of studies, we first specified a fixed-effects model without any between-study variation to pool the effect sizes. This model resulted in a small, positive, and statistically significant effect favoring boys, $g=0.12$, 


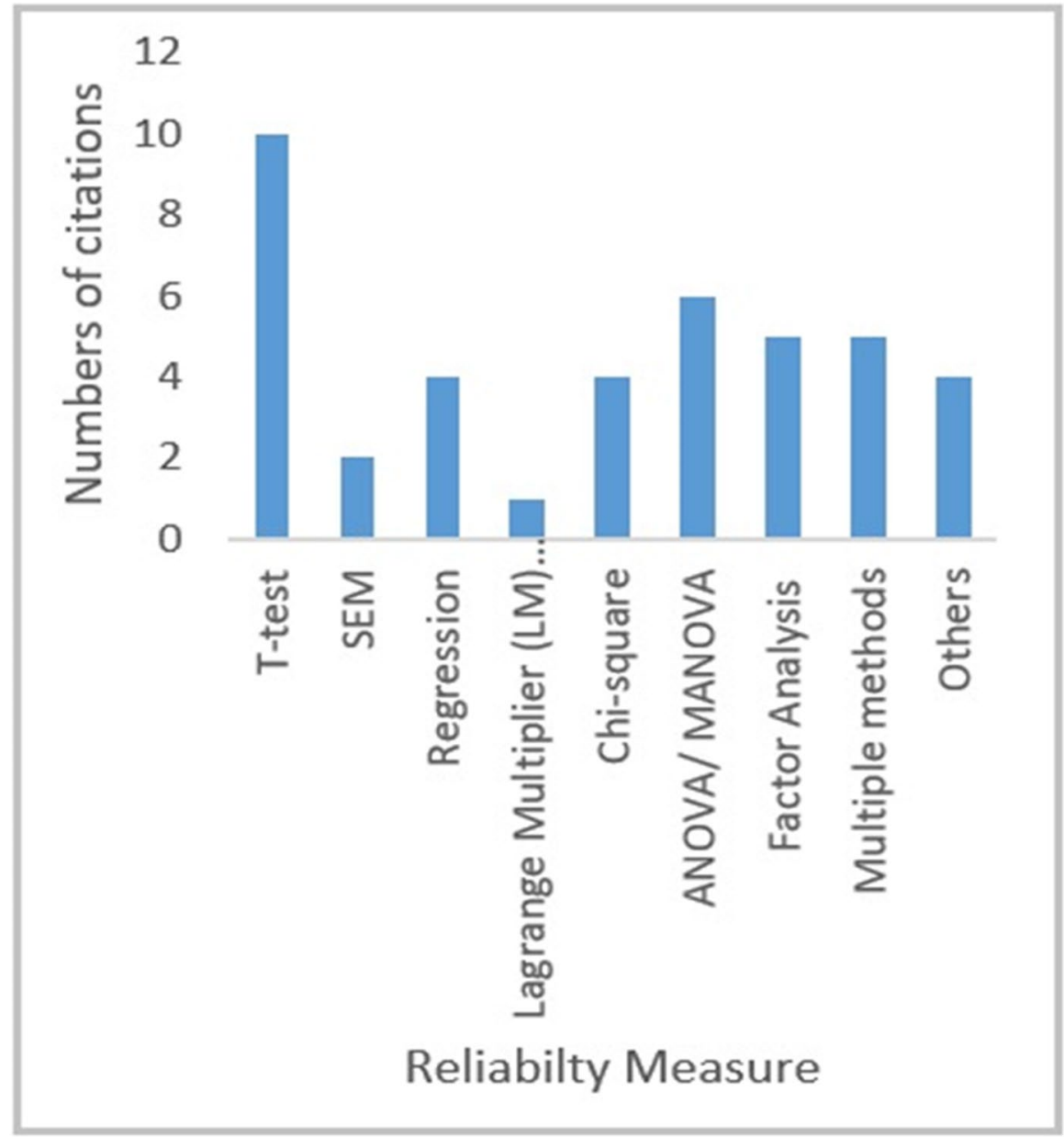

Fig. 9 Reliability measures

95\% CI [0.08, 0.15], $z=7.1, p<.001$. Second, we specified a random-effects model to quantify possible between-study variation in the effect sizes. Again, the overall effect size was small and positive, yet not statistically different from zero, $g=0.17,95 \%$ CI $[-0.02,0.36], z=2.0, p=.07$. The effect sizes varied significantly between the studies and exhibited substantial heterogeneity $\left(\tau^{2}=\right.$ $0.092,95 \%$ CI $\left.[0.044,0.290], \mathrm{I}^{2}=93.4 \%, Q[14]=210.9, p<.001\right)$. Figure 13 shows all effect sizes as well as the results of fixed- and random-effects modeling. Overall, these results did not indicate gender differences in the ICT-related variables. 


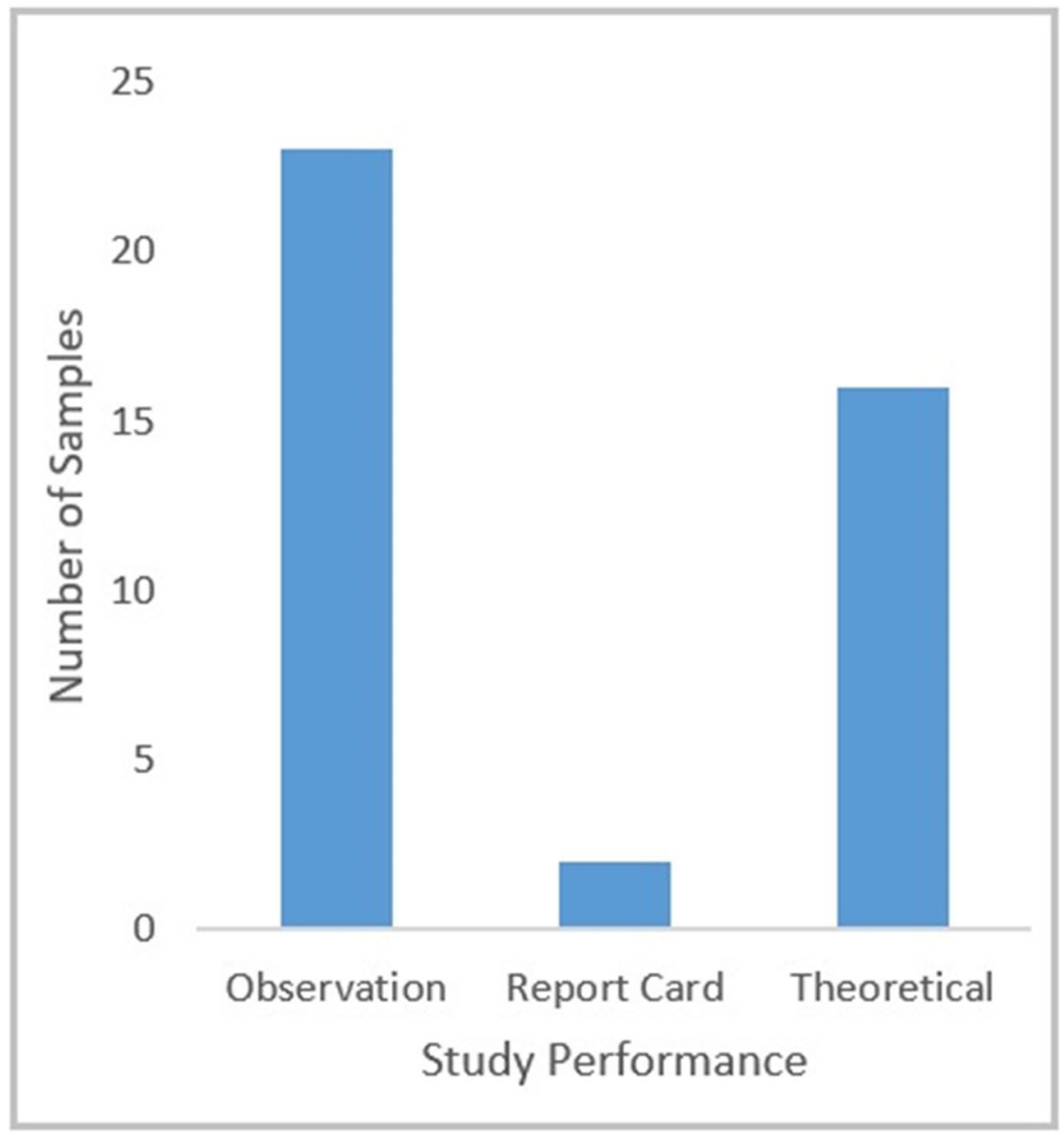

Fig. 10 Numbers of publications per test performance

\subsection{Publication \& selection bias}

To examine the degree of publication bias, we inspected the funnel plots for the standard errors and the respective inverse standard errors (Egger et al., 1997). The graphical representation of these plots (see Fig. 14) did not show substantial asymmetry in the plots. Subsequent trim-and-fill analyses suggested that only one effect size might be added to the left side of the plot to achieve better symmetry - the corresponding, corrected effect size was only marginally lower than that obtained from the initial random-effects model, $g=0.15,95 \%$ CI $[-0.02$, 0.32]. The rank correlation test did not show a relationship between effect sizes and sampling variances (Kendall's tau $=0.086, p=.697$ ), and Egger's regression test yielded a statistically insignificant test statistic. Furthermore, Rosenberg's 


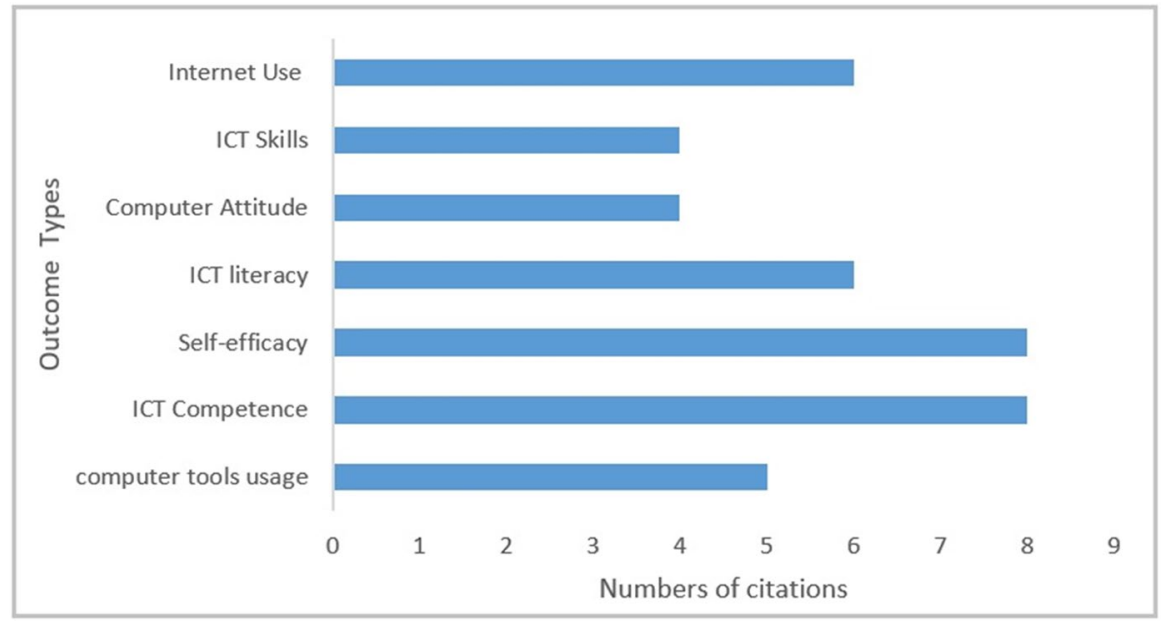

Fig. 11 Numbers of publications per test performance

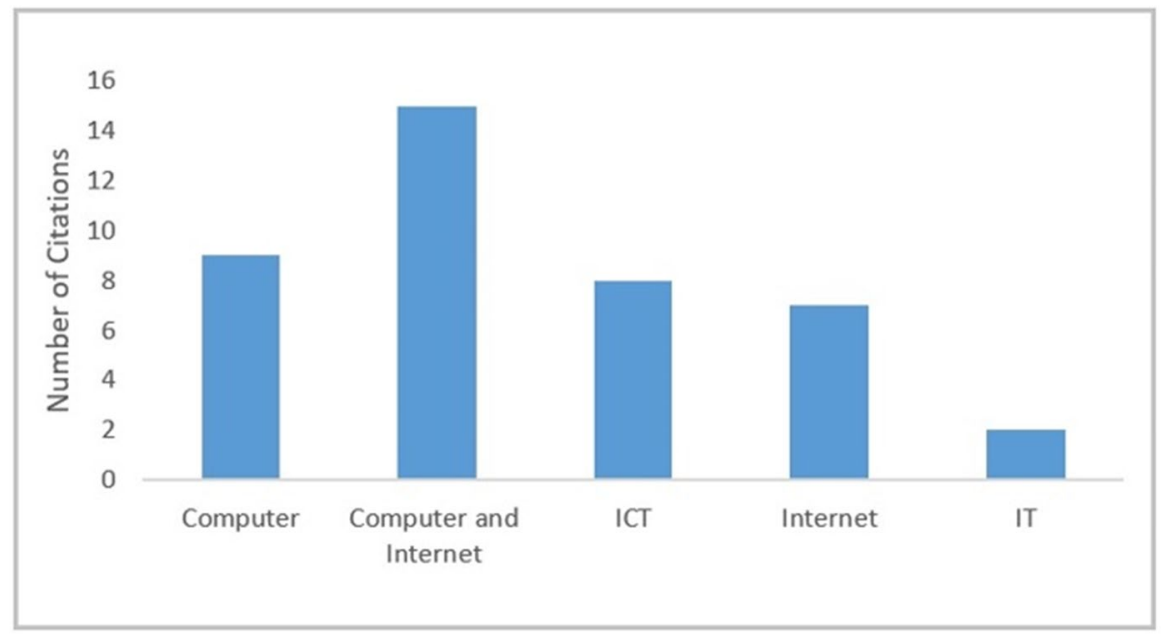

Fig. 12 Number of citations per category of tools for evaluation

fail-safe $N$ was 98 , that is, a large number of studies when compared to the number of independent samples $(k=15)$. Overall, these analyses indicate that publication bias was evident only to a minor extent (see Fig. 14). Finally, we inspected the $p$-curve underlying the sample of effect sizes and their respective $p$-values to rule out a possible selection bias (Simonsohn et al., 2014). This curve indicated that the set of studies selected for the meta-analysis had evidential value (see Fig. 15). 


\begin{tabular}{|c|c|c|c|c|c|}
\hline Study & $\begin{array}{c}\text { Standardised Mean } \\
\text { Difference }\end{array}$ & SMD & $95 \%-\mathrm{Cl}$ & $\begin{array}{l}\text { Weight } \\
\text { (fixed) }\end{array}$ & $\begin{array}{r}\text { Weight } \\
\text { (random) }\end{array}$ \\
\hline Aesaert (2015) & $\left.\rightarrow\right|_{1} ^{1}:$ & -0.38 & {$[-0.58 ;-0.17]$} & $2.5 \%$ & $6.9 \%$ \\
\hline Wong (2012) & - & 0.06 & {$[-0.20 ; 0.33]$} & $1.5 \%$ & $6.5 \%$ \\
\hline Lu et al. (2018) & 荬 & 0.10 & {$[0.00 ; 0.21]$} & $9.6 \%$ & $7.5 \%$ \\
\hline Esteve-Mon et al. (2020) & & 0.35 & {$[0.05 ; 0.65]$} & $1.2 \%$ & $6.2 \%$ \\
\hline Alakpodia (2014) & : & 0.54 & {$[0.26 ; 0.82]$} & $1.3 \%$ & $6.3 \%$ \\
\hline Tondeur et al. (2016) & $4:$ & -0.01 & {$[-0.14 ; 0.11]$} & $6.4 \%$ & $7.4 \%$ \\
\hline Hargittai \& Shafer (2006) & i: & -0.56 & {$[-0.96 ;-0.16]$} & $0.6 \%$ & $5.3 \%$ \\
\hline Kaarakainen (2017) & $+1:$ & -0.08 & {$[-0.13 ;-0.02]$} & $37.1 \%$ & $7.7 \%$ \\
\hline Meri-Tuulia Kaarakainen (2017)-1 & : & 0.40 & {$[0.33 ; 0.47]$} & $21.1 \%$ & $7.6 \%$ \\
\hline Meri-Tuulia Kaarakainen (2017)-2 & $\rightarrow$ & 0.68 & {$[0.50 ; 0.86]$} & $3.4 \%$ & $7.1 \%$ \\
\hline Imhof (2007) & $\longrightarrow$ & 0.75 & {$[0.16 ; 1.33]$} & $0.3 \%$ & $3.9 \%$ \\
\hline Vekiri \& Chronaki (2008) & $\frac{1}{10}$ & 0.29 & {$[0.08 ; 0.50]$} & $2.3 \%$ & $6.9 \%$ \\
\hline Su-yen (2009) & 乼 & 0.13 & {$[0.03 ; 0.24]$} & $9.6 \%$ & $7.5 \%$ \\
\hline Nai-li (2007)-1 & 萡 & 0.10 & {$[-0.16 ; 0.37]$} & $1.5 \%$ & $6.5 \%$ \\
\hline Nai-li (2007)-2 & 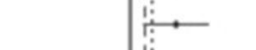 & 0.36 & {$[0.11 ; 0.62]$} & $1.6 \%$ & $6.6 \%$ \\
\hline Fixed effect model & 萡 & \multirow{4}{*}{\multicolumn{2}{|c|}{$\begin{array}{l}0.12[0.08 ; 0.15] \\
0.17[-0.01 ; 0.36]\end{array}$}} & $100.0 \%$ & \\
\hline Random effects model & $\dot{j}$ & & & - & $100.0 \%$ \\
\hline Heterogeneity: $I^{2}=93 \%, \tau^{2}=0.0918$ & & & & & \\
\hline & $\begin{array}{lll}-0.5 & 0 & 0.5\end{array}$ & & & & \\
\hline
\end{tabular}

Fig. 13 Forest plot of the effect sizes

\section{Discussion}

In light of our proposed research questions, this section will define the selected study's findings to provide adequate information and solution to the research questions. To answer RQs, we focus on analyzing the differences in our selected articles and investigating ICT use and related skills among students. This review produced several key findings that are discussed in detail here.

The study (Volman et al., 2005) looks at several forms of ICT-based applications in education for male and female students from ethnic minorities and the majority in the Netherlands. The gender difference in primary education is observed to be smaller than in secondary education. The girl's behavior seems to a lesser degree positive towards computers than boys at secondary education. It is also observed that the pupils from ethnic minority backgrounds are recognized to a lesser degree skilled at ICT in comparison with the majority population. Authors (Aesaert \& Van Braak, 2015) showed that, in general, students of primary schools faced more difficulties in advancing ICT competencies. Interestingly, the girls performed better in advance order ICT competencies than boys. The study (Milek et al., 2011) illustrated that in different regions in Africa, the students and other populations are surveyed, and overall, males dominate more than girls. The results revealed that socio-economic status, income, education, and employment are the most influential predictors that impact male and female access and use of ICT across all the seventeen African countries. The study by (Tømte \& Hatlevik, 2011) aims to identify the relationship between self-efficacy, ICT user profiles, and gender in Norway and Finland; six ICT user profiles were used for this study to differentiate between school and leisure 


\section{Standard Error}

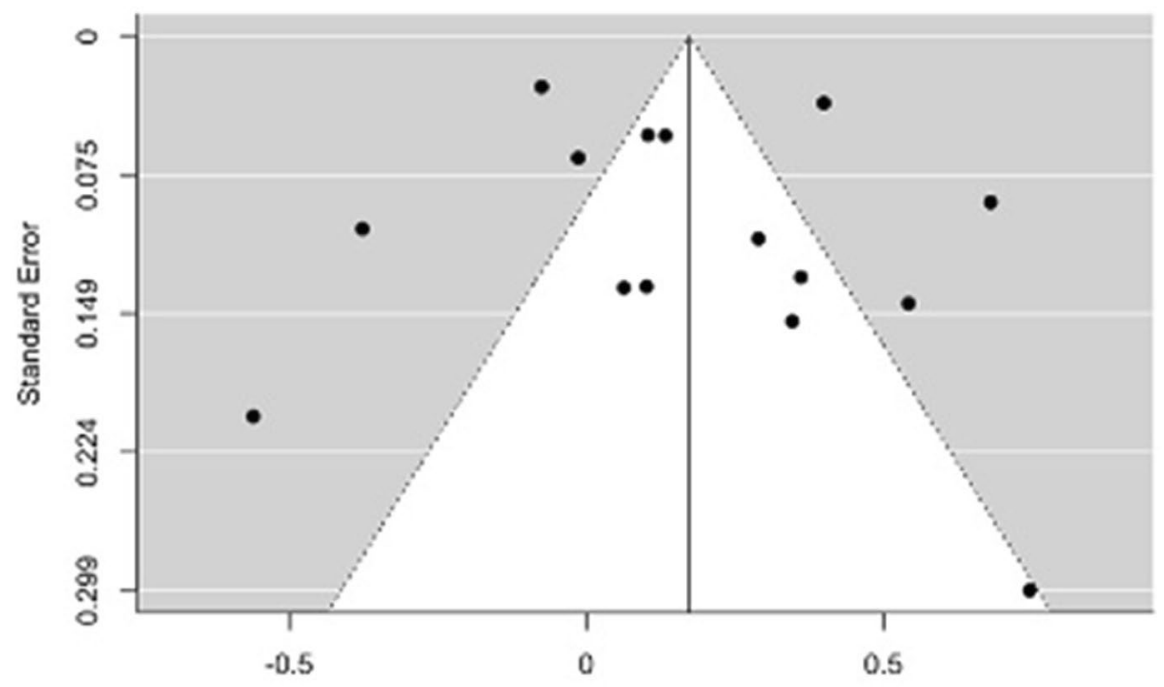

Standardized Mean Difference

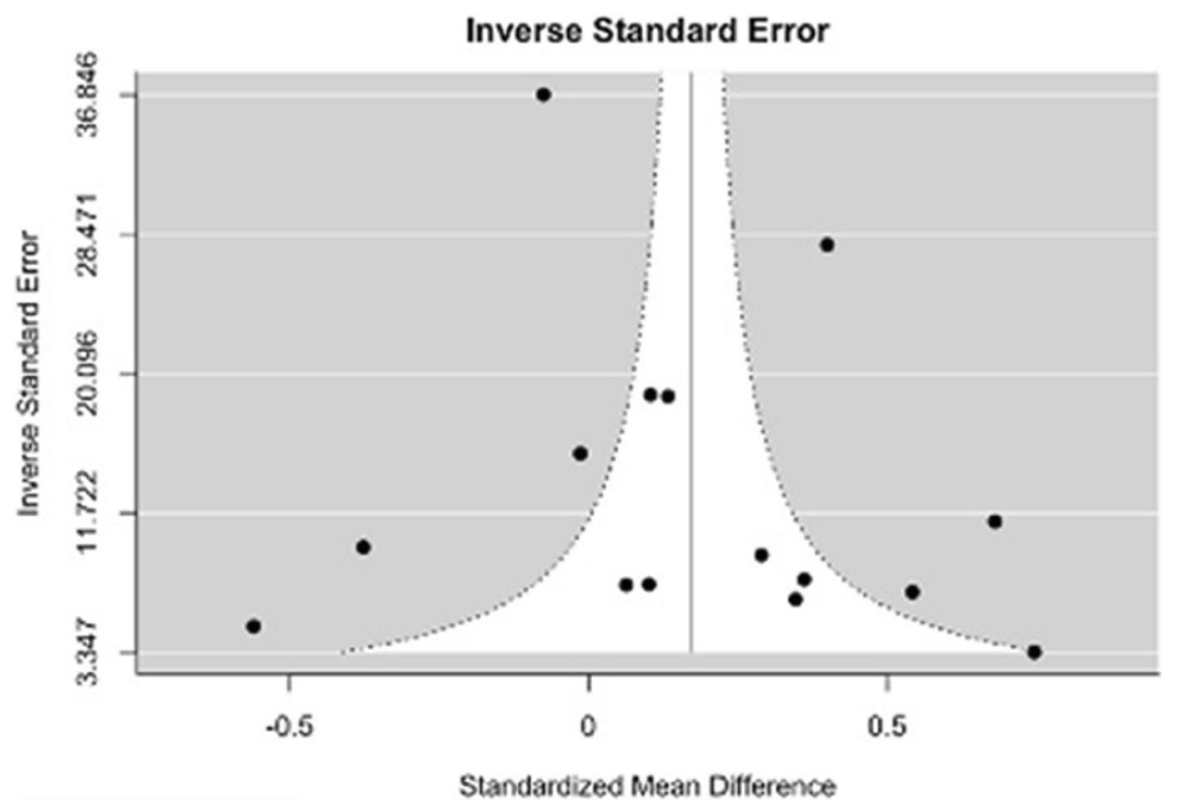

Fig. 14 Funnel plots based on the random-effects model

activities. The self-efficacy of students differed depending on the ICT user profile they were in. Findings explained the gender differences between high-level tasks and the use of the internet when comparing Norway and Finland. In comparison to 


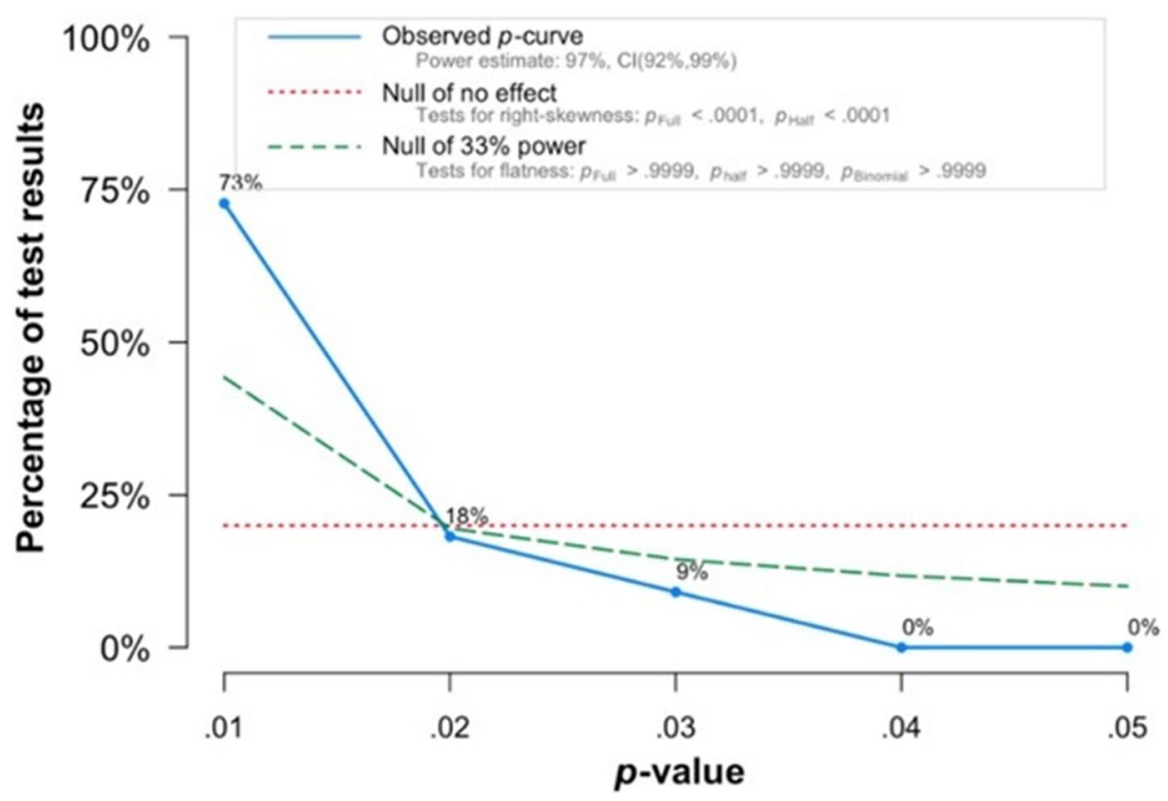

Fig. 15 P-curve

Finnish females and males, Norwegian females and males show higher self-efficacy in ICTs. Males, on the other hand, in Finland show higher levels of self-efficacy in ICT Internet and High-level tasks than females. Individualism-collectivism and gender differences play a moderating influence in the individual's adoption of mobile commerce, according to the study (Faqih \& Jaradat, 2015). The results showed a significant part of mobile adoption of individualism-moderation collectivism's role at individual-level values. However, during the adoption process, the gender shows no moderating effect. Teachers' computer self-efficacy (CSE) is being researched, with a combination of basic and advanced computer abilities being practiced for instructional reasons (Scherer \& Siddiq, 2015). In this case, the male teachers performed better in fundamental and advanced skills, but no significant difference is observed in using computers for instructional purposes. The study (Sáinz \& Eccles, 2012) has explored the self-concept of computer abilities in Spanish secondary school boys is two times higher than girls. It is also noted that boys' self-perception of computer aptitude increased over time, whereas girls' self-perception of computer ability dropped. In this study, the self-concepts of computer aptitude mediate with the association of gender to predict purchase intention of ICT-based products.

In the twenty-first century, preparing the students for successful lifelong learning ICT literacy is an important factor. To define the importance of measurement invariance in the context of ICT literacy, the study (Lau \& Yuen, 2015) tests the factorial invariance of newly developed factors across gender in China at secondary school, multiple-group confirmatory factor analysis framework is applied. The scale showed gender invariance in terms of customizable and partial measurement invariance, but not structural invariance. In junior-high-school students', 
the gender differences were examined (Tsai \& Tsai, 2010) for Internet self-efficacy (ISE) and the Internet's use. Online exploration (explorative ISE) and online communication are used to investigate students' Internet self-efficacy (communicative ISE). Overall, there was no notable difference noted in students' total ISE and explorative ISE. Though, in students' communicative ISE, a noteworthy gender difference was recorded. Unexpectedly, the girls showed higher significant communicative ISE than boys. The study related to gender differences in access to ICT among high-school students of Greece is carried out by (Papastergiou \& Solomonidou, 2005). The results presented that Internet usage is higher outside the school, such as Internet cafes and the home, compared to inside school Internet usage. It is also noted that in comparison to girls, boys have greater internet options. In a study (Sieverding \& Koch, 2009), participants have to observe a target person in the video who performs a complex task at a particular time. Then participants have to evaluate their skills. Results showed that no systematic gender-related bias occurs for the causal attribution of success and the target individuals' direct evaluation. However, according to self-ratings in computer-related tasks: (1) both female and male judged their hypothetical performance, and it is noted relatively higher when comparing it to the identically scripted performance as a girl versus compared to a boy; (2) girls analyzed their computer competence to be lesser than boys. A study (Hargittai \& Shafer, 2006) has tested the relationship between self-perceived abilities to actual abilities to use the Internet and found the measures of difference by gender. The sample consists of a variety of field experts, including students and teachers as well. Yet, it is noted that the female's self-assessed skill with Internet-use ability is significantly lower than that of the male. This lower self-assessment to use the Internet may significantly impact their online behavior and uses medium types.

The gender differences and new trends in accessing social media and online games are learned in South Korea (Lim \& Meier, 2011). Boys prefer playing multiuser online games with friends, notably in Internet cafés, whereas girls prefer social networking websites. The study (Hohlfeld et al., 2013), which examined gender differences in ICT literacy, indicates significant differences in females' favor. Females achieved a higher score in perception measures for computer use frequency, perceived ICT skills, and attitudes toward Computers. ICT use and access are differentiated based upon gender in the study (Cheung et al., 2013) proposed for Rio de Janeiro. It is believed that gender differences in ICT use highlight that females showed lower interest in ICT use and literacy. The gender difference is learned (da Silva \& Olinto, 2016) for digital reading performance in two scenarios favoring females. In the first scenario, there is a gender divide in Hong Kong when it comes to online reading, and their ICT use is for pleasure. The second example is digital reading literacy in Korea, where students' usage of ICT for leisure and online reading activities shows no student involvement. The study (Rashid, 2016) supports the claim that digital inequalities are due to social inequalities. In five nations, namely Bangladesh, Brazil, Chile, Ghana, and the Philippines, there is a clear gender gap in ICT access. Various variables, such as skills, user attitude, computers, and the Internet, were used to examine the gender gap. It's noted from the findings that compared with other countries, the female in Bangladesh suffers more from digital exclusion. 
Another study (Buabeng-Andoh \& Yidana, 2014) conducted for Africa (Ghana) showed male dominance in attitude towards ICT compared to a female.

The influence of gender difference on using ICT application (annotatable multimedia e-reader (AME)) was tested on learning before and after class (Liu et al., 2015). The results indicate female uses the learning tools more frequently than males. Likewise, a study related to the gender digital divide by supporting more females accesses ICT than males. Gender and IT theory were utilized to investigate gender stereotypes for knowledge and abilities in the IT field to better understand the gender imbalance (Trauth et al., 2016). The women students with nontechnical skills were found less masculine than men. To investigate the causes of gender variations in students' self-efficacy and value views, a study (Vekiri \& Chronaki, 2008) for elementary children in Greece looked at the relationships between boys' and girls' computer experiences, social support for using computers, and motivational views. Males received greater computer support, value attitudes, and positive computer self-efficacy from their parents and peers than females. Likewise, in a subsequent study, the gender gap in ICT abilities was discovered in the item-level analysis of a study of Finnish upper comprehensive school pupils (Kaarakainen et al., 2017). Boys scored higher on more technical-oriented questions in this study for explicit item-level analysis. Girls, on the other hand, scored higher on topics linked to schoolwork and social contact.

Furthermore, the study (Teo, 2008) examined the attitudes of 139 pre-service teachers towards the use of computers. The readings were noted on the Likert scale with four factors to use the computer: liking perceived control and usefulness, and behavioral intention. According to the findings, there were no gender or age variations in pre-service teachers' attitudes about computers. However, there were considerable disparities in the use of computers in subject areas such as Humanities, Sciences, Languages, and General (Primary). ICT competency of undergraduate students in China is tested to examine gender differences empirically (Wong $\&$ Cheung, 2012). The results are significantly supported by the argument that the social use of ICT in daily life may reduce or even remove the gender digital gap. The study (Alkan \& Erdem, 2010) was performed on 244 University students from diverse backgrounds, such as Biology, Chemistry, Mathematics, and Physics. The use of ICT towards education was measured by the "Attitude Scale towards Educational Technologies." The findings showed that regardless of gender or age, teaching application lessons had a favorable impact on students' use of educational tools. Student teachers who obtained teaching apps for educational technology, on the other hand, were more enthusiastic than student instructors who did not receive teaching apps. A comparison of 155 young Muslim women and men studying in three computer training centers in India was done (Khan \& Ghadially, 2010). Young women reported greater gains from computer learning combined with ICT in terms of perceived empowerment than men.

In the study (Ballesta Pagán et al., 2018), the students were monitored for ethnicity and gender both. The findings suggest that students who use the Internet and computers from other countries have less computer equipment at home, and many of them have a computer at home that is not connected to the Internet. In addition, the amount of time spent on computers and the Internet has decreased. Furthermore, 
there are substantial discrepancies in how females and males use the Internet; girls have rarely used it compared to boys, who use it to play online and at school. A subsequent study (Chou et al., 2011) employed confirmatory factor analysis (CFA) to examine the assumptions underlying the hypothetical 6-T (Tool, Toy, Telephone, Territory, Trade, and Treasure) model of information to describe college students' Internet-related attitudes. The analytical results reveal that gender made a significant difference in some factors of Internet-related attitudes. Male students scored higher on toy and telephone than female students $(\mathrm{p}<.05$ and $\mathrm{p}<.001)$. Female and male students, on the other hand, did not show any significant differences in the tool, territory, treasure of information, and trade factors of the attitude.

In the study (Schlebusch, 2018) concerning computer anxiety, attitude towards the Internet, and computer self-efficiency (CSE) to find the difference between male and female students, a sample t-test was applied. There was no statistically significant difference between males and females in terms of computer anxiety, Internet attitude, and CSE. However, there is a slight difference for CSE among high school students in South Africa; male students (mean=105.14317) were more than female students (mean $=100.29918$ ). During the years 2014-2016, an ICT competency test research was done in Finland with upper comprehensive and upper secondary school students $(n=3159)$ and their teachers $(n=626)$ (Kaarakainen et al., 2018). Three ICT skills components were constructed using factor analysis: basic digital skills, advanced technical skills, and professional ICT skills. Among the pupils, male students' average scores were greater than female students' average scores. The difference is not great, though, when it comes to basic digital skills. Significant differences were identified in advanced technical capabilities $(\mathrm{F}=245,111, \mathrm{df}=1, \mathrm{p}$ B.001) and professional ICT capabilities $(\mathrm{F}=234,537, \mathrm{df}=1, \mathrm{p}$ B.001). In a study conducted at higher education institutions in Papua New Guinea, gender differences in access, application, and attitudes toward information communication technology (ICT) were studied using a mixed-methods approach (Kolodziejczyk, 2015). There is a major gap in access to ICT applications; qualitative data revealed severe disparities entrenched in a male-dominated culture. In a study (Hatlevik et al., 2017) ICT literacy test was performed on Norwegian students. According to the multi-group confirmatory factor analysis results, the test had a sufficient amount of measurement in- variance across gender, allowing researchers to make meaningful comparisons. The comparisons show that girls have a higher ICT literacy than boys. In a subsequent study (Meelissen \& Drent, 2008), a large-scale Dutch survey on ICT use in elementary school, a teacher-centered educational method, and female teachers' computer experience are all explored. This role model theory is used to illustrate that having a female teacher with computer knowledge has a slight beneficial effect on girls' computing attitudes. Girls, on the other hand, perform better in computing attitude than guys in school. Furthermore, female instructors are significantly less confident than male instructors when it comes to using ICT in the classroom.

Moreover, the ICT use exploring skills and access was monitored for University students in and (Imhof et al., 2007) results show male dormancy in using the computer. In another study (Li \& Kirkup, 2007), a comparison between the UK and China students was performed. It is noted that gender inequalities in computer use were found to be greater in the British group than in the Chinese group. In a study 
(Chen \& Fu, 2009) among Taiwan students, the Internet's use also revealed a significant difference between girls and boys. The subsequent studies (Jackson et al., 2010) show a significant difference in ICT skills and use, and males performed better than girls in academia. Mixed-gender discussion groups had more dynamic interactions than other discussion group compositions, according to (Venkatesh et al., 2014). The direct effects of ICT skills and network involvement on male and female students' mathematical achievement were all negative. However, the indirect effects of the Internet self-efficacy adjustment factor were positive and significant (Lu et al., 2018). Differences in learning, ICT, and communication attitudes among subgroups established based on gender and academic accomplishment (Fabac et al., 2011) were statistically significant in the majority of cases. Furthermore, (Fabac et al., 2011) found that all subconstructs had significant levels of digital-age literacy proficiency. There are no significant differences between gender noted; however, there are considerable variances in students' attitudes about information privacy in research (Mohamud et al., 2015). The taxonomy of all these discussed studies is given in Table 6.

\section{Implications}

\subsection{Theoretical implications}

From the research point of view, this review study indicates an essential need for more empirical studies that use gender and socio-economic factors to identify ICT differences. There is little available research identified by (Aesaert \& Van Braak, 2015; Ballesta Pagán et al., 2018) on gender influenced by socio-economic factors incorporated with ICT differences. Hence, this is evident in the potential domain for a more in-depth understanding of socio-economic research for ICT differences to extend in-depth knowledge of ICT differences. In (Aesaert \& Van Braak, 2015), the noteworthy contribution to ICT research has discussed the rapid use of specific Apps on mobile devices and how they may influence the searching and processing of digital information and communication in unprecedented ways. Thus, future research needs to address the learner's needs related to these new ways of digital communication and information processing for the evaluation of the ICT applications. A study conducted by (Faqih \& Jaradat, 2015) contributes to a theoretical aspect of ICAIL (Individualism- collectivism at the individual level) that performed as a moderator in $\mathrm{m}$-commerce adoption. The study suggested that this contribution is important to highlight the need for further research by incorporating ICAIL factors, particularly for developing countries. The findings of (Lau \& Yuen, 2015) underlined the significance of measurement invariance as a methodological problem for researchers attempting to establish meaningful gender comparisons and interpretations in diverse situations in ICT in education literature.

Moreover, a study by (Lim \& Meier, 2011) recognized a need for research to focus on understanding varied usage and the implications of growing variations, notably in Korea and other high- digital-access countries. Stereotypes provide a solid basis for the adoption of gender theories within gender differences (Trauth 


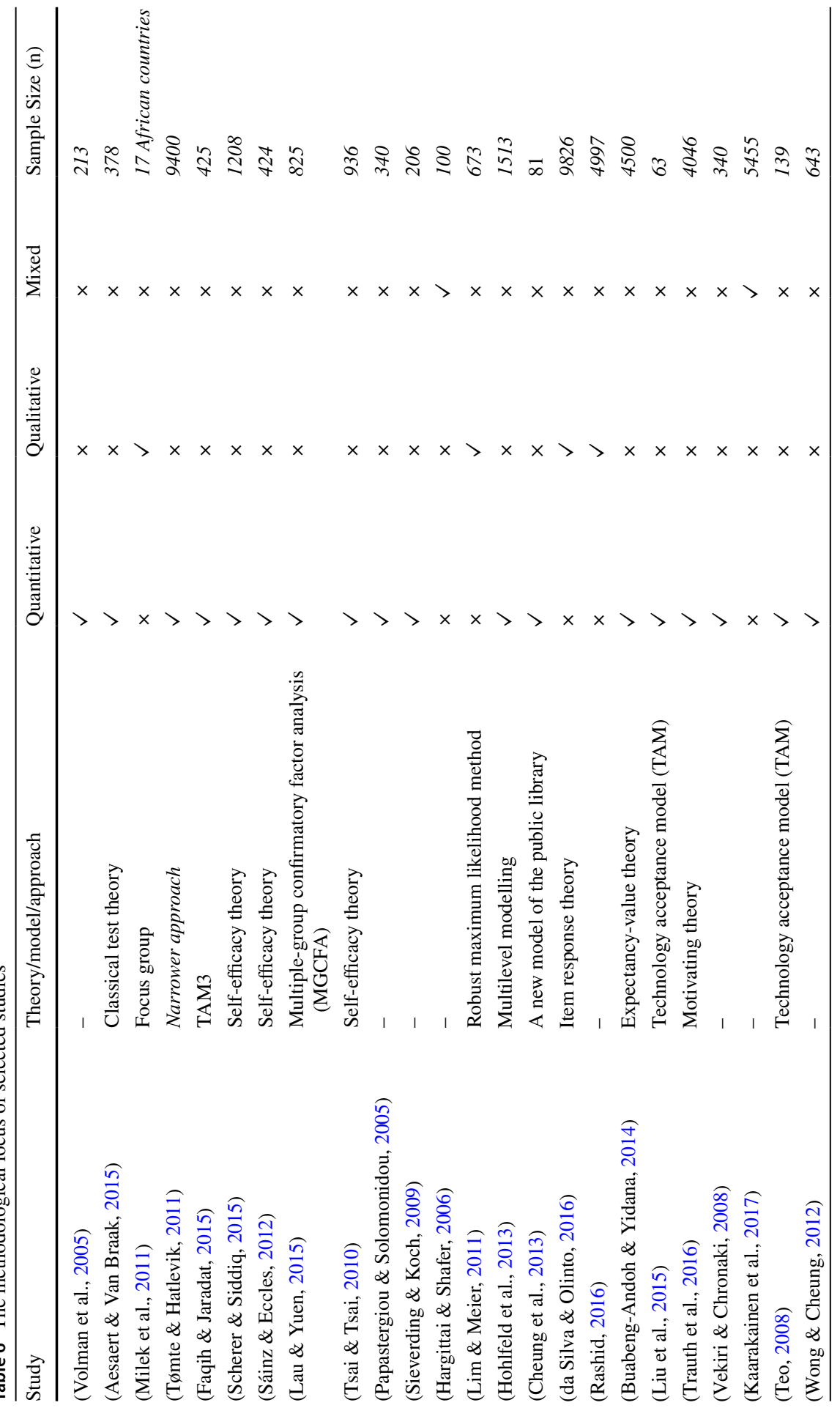




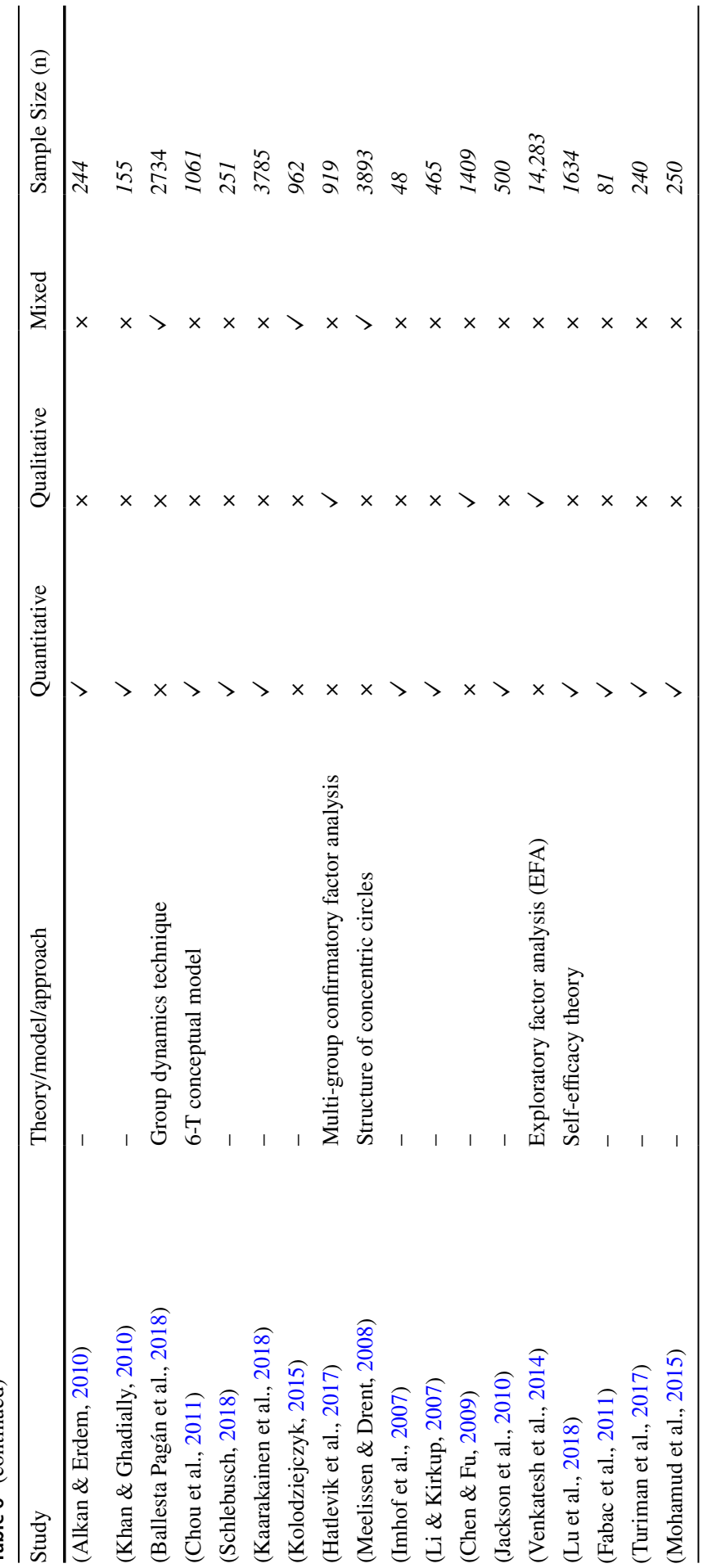


et al., 2016). To address gender stereotypes in the IT field, there is a need to reevaluate the design and application processes. Lastly, the proposed framework is employed as a meta-model to categorize the vast and mostly disparate literature that influences ICT access, use, and skills. In terms of the educational framework, certain recommendations are made to increase socio-educational fairness and inclusion in communities seeking a more sustainable form of growth.

\subsection{Practical implications}

Numerous practical implications, specifically about increasing acceptance and adoption of the computer-based system and mobile technology, were reported in several studies. For example, (Aesaert \& Van Braak, 2015) indicates that for ICT competencies, students need to know the fast changes in technology. To evaluate and increase ICT literacy among students of various genders (Sáinz \& Eccles, 2012) provides practical implications for instructors. Another possible implication discussed (Rashid, 2016) for researchers and policymakers is to reduce the "gender gap" and equality in access; rather the essential use of ICTs is to fulfill specific individual needs and motivations. From the equality perspective of males and females, (Milek et al., 2011) suggested a policy point of view to develop a legal framework that assures equal rights for men and women in terms of gender equality. This will protect them from discriminatory practices and foster equitable participation in society and the economy by men and females. Furthermore, authorities should expect an improvement in teachers' attitudes toward adopting ICT. This can be done by giving them the technology tools, training, and incentives they need to effectively use ICT in the classroom for the benefit of their pupils.

\section{Conclusion}

It is important to highlight the continued gender differences with significant gender biases towards access, use, and ICT skills. The article's demographic distribution discovered interesting results. For example, most studies investigated in this review were undertaken in North America and East Asia (Taiwan, China, South Korea, Hong Kong). The purpose of emphasizing these facts is to highlight the gaps and motivate future research into other regions. The quantitative survey methodology, in addition to mixed-method, was frequently used in all the discussed studies. Our findings exposed that most of the research was conducted on the gender-based ICT differences in the use and skills. It's worth noting that the education sector serves as a sample for comparing ICT differences. Our meta-analysis did not reveal gender differences in ICT use and skills and support, in part, the existing body of research. For future works, ethnicity, religion, and socio-economic differences could discuss and contrast different factors in forming a research model that formulated ICT differences taxonomy. In terms of the study's limitations, the efficiency of certain technological tools for pupils in different locations was not compared in this study. The lack of research studies in the field contributed to this constraint (Anderson, 2008). 


\section{Availability of data and material N/A}

\section{Code availability N/A}

Funding This work is supported by Universiti Brunei Darussalam under research grant UBD/RSCH/ URC/RG(b)/2020/023.

\section{Declarations}

Conflicts of interest/competing interests The authors declared no potential conflicts of interest concerning the research, authorship, and/or publication of this article.

\section{References}

Aesaert, K., \& Van Braak, J. (2015). Gender and socioeconomic related differences in performance based ICT competences. Computers \& Education, 84, 8-25.

Alkan, F., \& Erdem, E. (2010). The attitudes of student teachers towards educational technologies according to their status of receiving teaching application lessons. Procedia-Social and Behavioral Sciences, 2(2), 2523-2527.

Anandhita, V. H., \& Ariansyah, K. (2018). Gender inequality on the internet access and use in Indonesia: evidence and implications. 2018 International Conference on ICT for Rural Development (IC-ICTRuDev),

Anderson, R. E. (2008). Implications of the information and knowledge society for education. In International handbook of information technology in primary and secondary education (pp. 5-22). Springer.

Asad, M. M., Hussain, N., Wadho, M., Khand, Z. H., \& Churi, P. P. J. J. O. A. R. I. H. E. (2020). Integration of e-learning technologies for interactive teaching and learning process: An empirical study on higher education institutes of Pakistan.

Ashraf, M. M., Hasan, N., Lewis, L., Hasan, M. R., \& Ray, P. (2017). A Systematic Literature Review of the Application of Information Communication Technology for Visually Impaired People. International Journal of Disability Management, 11, e6, Article e6. https://doi.org/10.1017/idm.2016.6

Balduzzi, S., Rücker, G., \& Schwarzer, G. J. E.-B. M. H. (2019). How to perform a meta-analysis with R: a practical tutorial. 22(4), 153-160.

Ballesta Pagán, F. J., Lozano Martínez, J., \& Cerezo Máiquez, M. C. (2018). Internet use by secondary school students: A digital divide in sustainable societies? Sustainability, 10(10), 3703.

Basavaraja, M., Sampath Kumar, B. J. J.o.I. S. T. \& Practice. (2017). Gender disparities in the use of ICT: a survey of students in urban schools. 5(4), 39-48.

Borenstein, M., Higgins, J. P., Hedges, L. V., \& Rothstein, H. R. J. R. s. m (2017). Basics of meta-analysis: $\mathrm{I} 2$ is not an absolute measure of heterogeneity. 8(1), 5-18.

Brereton, P., Kitchenham, B. A., Budgen, D., Turner, M., Khalil, M. J. J. O. S, \& software. (2007). Lessons from applying the systematic literature review process within the software engineering domain. 80(4), 571-583.

Buabeng-Andoh, C., \& Yidana, I. (2014). An investigation of secondary school students' attitudes toward pedagogical use of ICT in learning in Ghana. Interactive Technology and Smart Education.

Button, D., Harrington, A., \& Belan, I. J. N. E. T. (2014). E-learning \& information communication technology (ICT) in nursing education: A review of the literature. 34(10), 1311-1323.

Chen, S.-Y., \& Fu, Y.-C. (2009). Internet use and academic achievement: Gender differences in early adolescence. Adolescence, 44(176).

Cheung, K.-C., Mak, S.-K., \& Sit, P.-S. (2013). Online reading activities and ICT use as mediating variables in explaining the gender difference in digital reading literacy: Comparing Hong Kong and Korea. The Asia-Pacific Education Researcher, 22(4), 709-720.

Chou, C., Wu, H.-C., \& Chen, C.-H. (2011). Re-visiting college students' attitudes toward the internetbased on a 6-T model: Gender and grade level difference. Computers \& Education, 56(4), 939-947.

Cohen, J. J. P. B (1992). A power primer. 112(1), 155. 
da Silva, A. G., \& Olinto, G. (2016). Gender differences in ICT use and information literacy in public libraries: a study in a Rio de Janeiro public library. European Conference on Information Literacy,

Deshpande, S., \& Shesh, A. (2021). Blended Learning and Analysis of Factors Affecting the Use of ICT in Education. In Next Generation Information Processing System (pp. 311-324). Springer.

Dieste, O., Grimán, A., \& Juristo, N. (2009). Developing search strategies for detecting relevant experiments. Empirical Software Engineering, 14(5), 513-539.

Egger, M., Smith, G. D., Schneider, M., \& Minder, C. J. B. (1997). Bias in meta-analysis detected by a simple, graphical test. 315(7109), 629-634.

Elo, S., \& Kyngäs, H. J. J. O. A. N. (2008). The qualitative content analysis process. 62(1), 107-115.

Fabac, R., Vidacek-Hains, V., \& Pazur, K. (2011). Attitudes of undergraduate students with regards to the information and communication aspects of study. Proceedings of the ITI 2011, 33rd International Conference on Information Technology Interfaces,

Faqih, K. M., \& Jaradat, M.-I. R. M. (2015). Assessing the moderating effect of gender differences and individualism-collectivism at individual-level on the adoption of mobile commerce technology: TAM3 perspective. Journal of Retailing and Consumer Services, 22, 37-52.

Fleiss, J. L., Levin, B., \& Paik, M. C. (2013). Statistical methods for rates and proportions. john wiley \& sons.

Fleiss, J. L., Levin, B., Paik, M. C. J. S. M. F. R., \& proportions. (1981). The measurement of interrater agreement. 2(212-236), 22-23.

Forbes, H., Oprescu, F. I., Downer, T., Phillips, N. M., McTier, L., Lord, B., . . Dayton, J. J. N. E. T. (2016). Use of videos to support teaching and learning of clinical skills in nursing education: A review. 42, 53-56.

Gnambs, T. J. C. I. H. B. (2021). The development of gender differences in information and communication technology (ICT) literacy in middle adolescence. 114, 106533.

Guilhamon, P., Eskandarpour, M., Halai, D., Wilson, G. A., Feber, A., Teschendorff, A. E., . . . Amary, M. F. J. N. C. (2013). Meta-analysis of IDH-mutant cancers identifies EBF1 as an interaction partner for TET2. 4(1), 1-9.

Hargittai, E., \& Shafer, S. (2006). Differences in actual and perceived online skills: The role of gender. Social Science Quarterly, 87(2), 432-448.

Hasan, N., \& Bao, Y. (2020). Impact of "e-learning crack-up" perception on psychological distress among college students during COVID-19 pandemic: A mediating role of "fear of academic year loss". Children and Youth Services Review, 118, 105355. https://doi.org/10.1016/j.childyouth.2020. 105355

Hatlevik, O. E., Scherer, R., \& Christophersen, K.-A. (2017). Moving beyond the study of gender differences: An analysis of measurement invariance and differential item functioning of an ICT literacy scale. Computers \& Education, 113, 280-293.

Hohlfeld, T. N., Ritzhaupt, A. D., \& Barron, A. E. (2013). Are gender differences in perceived and demonstrated technology literacy significant? It depends on the model. Educational Technology Research and Development, 61(4), 639-663.

Imhof, M., Vollmeyer, R., \& Beierlein, C. (2007). Computer use and the gender gap: The issue of access, use, motivation, and performance. Computers in Human Behavior, 23(6), 2823-2837.

Jackson, L. A., von Eye, A., Fitzgerald, H. E., Zhao, Y., \& Witt, E. A. (2010). Self-concept, self-esteem, gender, race and information technology use. Computers in Human Behavior, 26(3), 323-328.

Kaarakainen, M.-T., Kivinen, A., \& Kaarakainen, S.-S. (2017). Differences between the genders in ICT skills for Finnish upper comprehensive school students: Does gender matter? Seminar. net,

Kaarakainen, M.-T., Kivinen, O., \& Vainio, T. (2018). Performance-based testing for ICT skills assessing: A case study of students and teachers' ICT skills in Finnish schools. Universal Access in the Information Society, 17(2), 349-360.

Karakostantaki, E., Stavrianos, K. J. E., \& Technologies, I. (2021). The use of ICT in teaching religious education in primary school. 26(3), 3231-3250.

Keele, S. (2007). Guidelines for performing systematic literature reviews in software engineering.

Khan, F., \& Ghadially, R. (2010). Empowerment through ICT education, access and use: A gender analysis of Muslim youth in India. Journal of International Development, 22(5), 659-673.

Kolodziejczyk, I. (2015). Mixed methods for study of gender issues in access, application, and attitudes toward ICT in higher education institutions in Papua New Guinea. SAGE Open, 5(2), 2158244015581017. 
König, J., Jäger-Biela, D. J., \& Glutsch, N. J. E. J. O. T. E (2020). Adapting to online teaching during COVID-19 school closure: teacher education and teacher competence effects among early career teachers in Germany. 43(4), 608-622.

Lahti, M., Hätönen, H., \& Välimäki, M. J. I. J. O. N. S (2014). Impact of e-learning on nurses’ and student nurses knowledge, skills, and satisfaction: a systematic review and meta-analysis. 51(1), 136-149.

Landis, J. R., \& Koch, G. G. J. B. (1977). The measurement of observer agreement for categorical data. 159-174.

Lau, W. W. F., \& Yuen, A. H. K. (2015). Factorial invariance across gender of a perceived ICT literacy scale. Learning and Individual Differences, 41, 79-85. https://doi.org/10.1016/j.lindif.2015. 06.001

Lee, C. C., Czaja, S. J., Moxley, J. H., Sharit, J., Boot, W. R., Charness, N., \& Rogers, W. A. (2019). Attitudes toward computers across adulthood from 1994 to 2013. The Gerontologist, 59(1), 22-33.

Lei, H., Xiong, Y., Chiu, M. M., Zhang, J., Cai, Z. J. C., \& Review, Y. S. (2021). The relationship between ICT literacy and academic achievement among students: A meta-analysis. 127, 106123.

Li, N., \& Kirkup, G. (2007). Gender and cultural differences in internet use: A study of China and the UK. Computers \& Education, 48(2), 301-317.

Lim, K., \& Meier, E. B. (2011). Different but similar: Computer use patterns between young Korean males and females. Educational Technology Research and Development, 59(4), 575.

Lipsey, M. W., \& Wilson, D. B. (2001). Practical meta-analysis. SAGE publications, Inc.

Liu, G.-Z., Wu, N.-W., \& Chen, Y.-W. J. R. I. D. D. (2013). Identifying emerging trends for implementing learning technology in special education. A state-of-the-art review of selected articles published in 2008-2012., 34(10), 3618-3628.

Liu, Y.-F., Hwang, W.-Y., \& Chen, S. (2015). The effects of gender differences on the use of annotatable multimedia e-readers. The Electronic Library.

Losh, S. C. J. I., \& Society. (2003). Gender and educational digital chasms in computer and internet access and use over time: 1983-2000. 1(4), 73-86.

Lu, C., Yang, X., \& Wu, D. (2018). ICT Competency, network interaction, internet self-efficacy, and mathematical achievement: Direct and mediating effects. 2018 IEEE International Conference on Teaching, Assessment, and Learning for Engineering (TALE),

Martin, F., Sun, T., Westine, C. D. J. C., \& education. (2020). A systematic review of research on online teaching and learning from 2009 to 2018. 159, 104009.

Meelissen, M. R., \& Drent, M. (2008). Gender differences in computer attitudes: Does the school matter? Computers in Human Behavior, 24(3), 969-985.

Milek, A., Stork, C., \& Gillwald, A. (2011). Engendering communication: a perspective on ICT access and usage in Africa. info.

Mohamud, I. K., Zeki, A. M., \& Saidin, A. Z. (2015). Attitude towards information privacy issues among students of IIUM. 2015 4th International Conference on Advanced Computer Science Applications and Technologies (ACSAT),

Moher, D., Liberati, A., Tetzlaff, J., Altman, D. G., \& therapy, P. G. J. P (2009). Reprint-preferred reporting items for systematic reviews and meta-analyses: the PRISMA statement. 89(9), 873-880.

Mumporeze, N., \& Prieler, M. (2017). Gender digital divide in Rwanda: A qualitative analysis of socioeconomic factors. Telematics and Informatics, 34(7), 1285-1293. https://doi.org/10.1016/j.tele. 2017.05.014

Nketiah-Amponsah, E., Asamoah, M. K., Allassani, W., \& Aziale, L. K. (2017). Examining students' experience with the use of some selected ICT devices and applications for learning and their effect on academic performance. Journal of Computers in Education, 4(4), 441-460.

Oldeweme, A., Märtins, J., Westmattelmann, D., \& Schewe, G. J. J. o. m. I. r. (2021). The role of transparency, trust, and social influence on uncertainty reduction in times of pandemics: empirical study on the adoption of COVID-19 tracing apps. 23(2), e25893.

Papastergiou, M., \& Solomonidou, C. (2005). Gender issues in internet access and favourite internet activities among Greek high school pupils inside and outside school. Computers \& Education, 44(4), 377-393. https://doi.org/10.1016/j.compedu.2004.04.002

Petty, J. J. N. E. T. (2013). Interactive, technology-enhanced self-regulated learning tools in healthcare education. A literature review., 33(1), 53-59.

Pimmer, C., Mateescu, M., \& Gröhbiel, U. J. C. I. H. B. (2016). Mobile and ubiquitous learning in higher education settings. A systematic review of empirical studies., 63, 490-501. 
Qazi, A., Fayaz, H., \& Raj, R. G. (2014a). Discourse on data mining applications to design renewable energy systems. Proceedings of International Conference on Advances in Engineering and Technology (ICAET'2014), Singapore,

Qazi, A., Fayaz, H., Wadi, A., Raj, R. G., Rahim, N., \& Khan, W. A. J. J. O. C. P (2015). The artificial neural network for solar radiation prediction and designing solar systems: a systematic literature review. 104, 1-12.

Qazi, A., Hardaker, G., Ahmad, I. S., Darwich, M., Maitama, J. Z., \& Dayani, A. J. I. A. (2021a). The Role of Information \& Communication Technology in Elearning Environments: A Systematic Review. 9, 45539-45551.

Qazi, A., Hussain, F., Rahim, N. A., Hardaker, G., Alghazzawi, D., Shaban, K., \& Haruna, K. J. I. A. (2019). Towards sustainable energy: a systematic review of renewable energy sources, technologies, and public opinions. 7, 63837-63851.

Qazi, A., Naseer, K., Qazi, J., AlSalman, H., Naseem, U., Yang, S., . . Review, Y. S. (2020). Conventional to online education during COVID-19 pandemic: Do develop and underdeveloped nations cope alike. 119, 105582.

Qazi, A., Qazi, J., Naseer, K., Zeeshan, M., Qazi, S., Abayomi-Alli, O., . . Review, Y. S. (2021b). Adaption of distance learning to continue the academic year amid COVID-19 lockdown. 126, 106038.

Qazi, A., Raj, R. G., Hardaker, G., \& Standing, C. J. I. R. (2017). A systematic literature review on opinion types and sentiment analysis techniques: Tasks and challenges.

Qazi, A., Raj, R. G., Tahir, M., Cambria, E., \& Syed, K. B. S. J. T. S. W. J. (2014b). Enhancing business intelligence by means of suggestive reviews. 2014.

Qazi, A., Raj, R. G., Tahir, M., \& Naqvi, S. G. A. (2013). A framework of review analysis for enhancement of business decision making. 2013 IEEE 13th International Conference on Data Mining Workshops,

Qazi, A., Raj, R. G., Tahir, M., Waheed, M., Khan, S. U. R., \& Abraham, A. J. T. S. W. J. (2014c). A preliminary investigation of user perception and behavioral intention for different review types: Customers and designers perspective. 2014.

Qazi, A., Syed, K. B. S., Raj, R. G., Cambria, E., Tahir, M., \& Alghazzawi, D. J. C. I. H. B (2016). A concept-level approach to the analysis of online review helpfulness. 58, 75-81.

Rahiem, M. D. J. U. J. O. E. R. (2020). Technological barriers and challenges in the use of ICT during the COVID-19 emergency remote learning. 8(11B), 6124-6133.

Rasheed, R. A., Kamsin, A., Abdullah, N. A., Zakari, A., \& Haruna, K. J. I. A. (2019). A systematic mapping study of the empirical MOOC literature. 7, 124809-124827.

Rasheed, R. A., Kamsin, A., Abdullah, N. A. J. C., \& Education. (2020). Challenges in the online component of blended learning: A systematic review. 144, 103701.

Rasheed, R. A., Kamsin, A., \& Abdullah, N. A. J. I. A. (2021). An Approach for Scaffolding Students Peer-Learning Self-Regulation Strategy in the Online Component of Blended Learning. 9, 30721-30738.

Rashid, A. T. (2016). Digital inclusion and social inequality: Gender differences in ICT access and use in five developing countries. Gender, Technology and Development, 20(3), 306-332.

River, J., Currie, J., Crawford, T., Betihavas, V., \& Randall, S. J. N. E. T (2016). A systematic review examining the effectiveness of blending technology with team-based learning. 45, 185-192.

Sáinz, M., \& Eccles, J. (2012). Self-concept of computer and math ability: Gender implications across time and within ICT studies. Journal of Vocational Behavior, 80(2), 486-499. https://doi.org/10. 1016/j.jvb.2011.08.005

Scherer, R., \& Siddiq, F. (2015). Revisiting teachers' computer self-efficacy: A differentiated view on gender differences. Computers in Human Behavior, 53, 48-57.

Schlebusch, C. L. (2018). Computer anxiety, computer self-efficacy and attitudes towards the internet of first year students at a south African university of technology. Africa Education Review, 15(3), 72-90.

Seuring, S., \& Müller, M. J. J. O. C. P (2008). From a literature review to a conceptual framework for sustainable supply chain management. 16(15), 1699-1710.

Siddiq, F., \& Scherer, R. (2019a). Is there a gender gap? A meta-analysis of the gender differences in students' ICT literacy. Educational Research Review, 27, 205-217. https://doi.org/10.1016/j.edurev. 2019.03.007

Siddiq, F., \& Scherer, R. J. E. R. R. (2019b). Is there a gender gap? A meta-analysis of the gender differences in students' ICT literacy., 27, 205-217. 
Sieverding, M., \& Koch, S. C. (2009). (self-)evaluation of computer competence: How gender matters. Computers \& Education, 52(3), 696-701. https://doi.org/10.1016/j.compedu.2008.11.016

Simonsohn, U., Nelson, L. D., \& Simmons, J. P. J. J. O. E. P. G (2014). P-curve: a key to the file-drawer. 143(2), 534.

Sinclair, P. M., Kable, A., Levett-Jones, T., \& Booth, D. J. I. J. O. N. S (2016). The effectiveness of Internet-based e-learning on clinician behaviour and patient outcomes: a systematic review. 57, 70-81.

Stevenson, M. P., Hartmeyer, R., \& Bentsen, P. J. E. R. R. (2017). Systematically reviewing the potential of concept mapping technologies to promote self-regulated learning in primary and secondary science education. 21, 1-16.

Tam, H.-L., Chan, A. Y.-F., \& Lai, O. L.-H. (2020). Gender stereotyping and STEM education: Girls' empowerment through effective ICT training in Hong Kong. Children and Youth Services Review, 119, 105624. https://doi.org/10.1016/j.childyouth.2020.105624

Teo, T. (2008). Pre-service teachers' attitudes towards computer use: A Singapore survey. Australasian Journal of Educational Technology, 24(4).

Tømte, C., \& Hatlevik, O. E. (2011). Gender-differences in self-efficacy ICT related to various ICT-user profiles in Finland and Norway. How do self-efficacy, gender and ICT-user profiles relate to findings from PISA 2006. Computers \& Education, 57(1), 1416-1424.

Trauth, E. M., Cain, C. C., Joshi, K. D., Kvasny, L., \& Booth, K. M. (2016). The influence of gender-ethnic intersectionality on gender stereotypes about IT skills and knowledge. ACM SIGMIS Database: the DATABASE for Advances in Information Systems, 47(3), 9-39.

Tsai, M.-J., \& Tsai, C.-C. (2010). Junior high school students' internet usage and self-efficacy: A reexamination of the gender gap. Computers \& Education, 54(4), 1182-1192. https://doi.org/10. 1016/j.compedu.2009.11.004

Turiman, P., Osman, K., \& Wook, T. S. M. T. (2017). Digital age literacy proficiency among science preparatory course students. 2017 6th International Conference on Electrical Engineering and Informatics (ICEEI),

Vekiri, I., \& Chronaki, A. (2008). Gender issues in technology use: Perceived social support, computer self-efficacy and value beliefs, and computer use beyond school. Computers \& Education, 51(3), 1392-1404.

Venkatesh, V., Croteau, A.-M., \& Rabah, J. (2014). Perceptions of effectiveness of instructional uses of technology in higher education in an era of Web 2.0. 2014 47th Hawaii international conference on system sciences,

Viechtbauer, W. J. J. O. S. S (2010). Conducting meta-analyses in R with the metafor package. 36(3), $1-48$.

Volman, M., Van Eck, E., Heemskerk, I., Kuiper, E. J. C., \& Education. (2005). New technologies, new differences. Gender and ethnic differences in pupils' use of ICT in primary and secondary education., 45(1), 35-55.

Voutilainen, A., Saaranen, T., \& Sormunen, M. J. N. E. T (2017). Conventional vs. e-learning in nursing education: A systematic review and meta-analysis. 50, 97-103.

Webb, L., Clough, J., O’Reilly, D., Wilmott, D., \& Witham, G. J. N. E. T. (2017). The utility and impact of information communication technology (ICT) for pre-registration nurse education: A narrative synthesis systematic review. 48, 160-171.

White, A., \& Schmidt, K. J. C. T. I. M. (2005). Systematic literature reviews. 13(1), 54-60.

Wilhelm, C. J. I., Communication, \& Society. (2018). Gender role orientation and gaming behavior revisited: examining mediated and moderated effects. 21(2), 224-240.

Wong, K. C., \& Cheung, W. K. (2012). A study of gender differences in ICT competency. 2012 8th International Conference on Information Science and Digital Content Technology (ICIDT2012),

Xia, L., Zhong, B. J. C., \& Education. (2018). A systematic review on teaching and learning robotics content knowledge in K-12. 127, 267-282.

Zafar, S., Safdar, S., \& Zafar, A. N. J. E. J. O. R (2014). Evaluation of use of e-learning in undergraduate radiology education: a review. 83(12), 2277-2287.

Publisher's note Springer Nature remains neutral with regard to jurisdictional claims in published maps and institutional affiliations. 


\section{Authors and Affiliations}

Atika Qazi ${ }^{1}$ - Najmul Hasan ${ }^{2}$. Olusola Abayomi-Alli ${ }^{3}$. Glenn Hardaker ${ }^{1}$. Ronny Scherer ${ }^{4}$. Yeahia Sarker ${ }^{5}$. Sanjoy Kumar Paul ${ }^{6}$. Jaafar Zubairu Maitama ${ }^{7}$

1 Center for lifelong learning, Universiti Brunei Darussalam, Gadong, Brunei

2 Center for Modern Information Management, School of Management, Huazhong University of Science and Technology, Wuhan 430074, People's Republic of China

3 Department of Software Engineering, Kaunas University of Technology, Kaunas, Lithuania

4 Centre for Educational Measurement at the University of Oslo (CEMO), Faculty of Educational Sciences, University of Oslo, Oslo, Norway

5 Department of Mechatronics Engineering, Rajshahi University of Engineering \& Technology, Rajshahi 6204, Bangladesh

6 UTS Business School, University of Technology Sydney, Sydney, Australia

7 Department of Information Technology, Faculty of Computer Science and Information Technology, Bayero University Kano, Kano, Nigeria 